BANCA D'ITALIA

E U R O S I S T E M A

Temi di discussione

(Working Papers)

Whatever it takes to save the planet?

Central banks and unconventional green policy

by Alessandro Ferrariand Valerio Nispi Landi

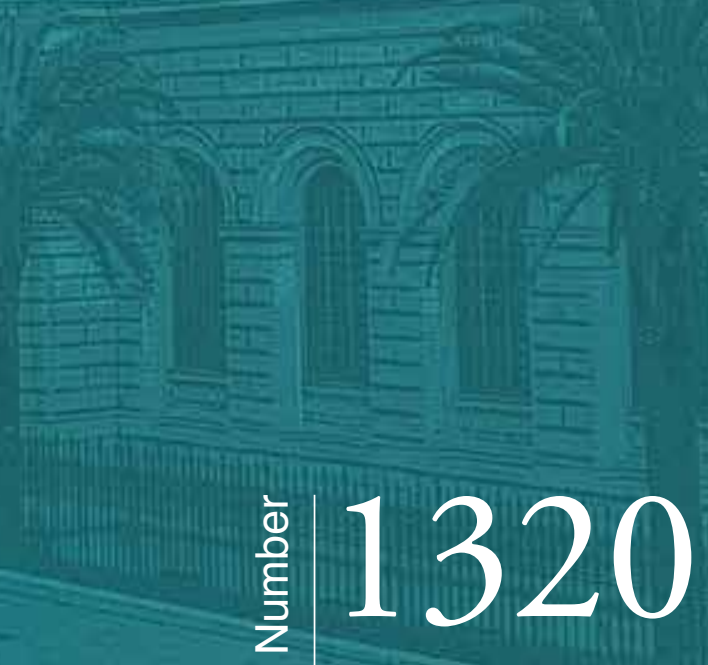



13 BANCA D'ITALIA

E U ROS I S T E M A

\section{Temi di discussione}

(Working Papers)

Whatever it takes to save the planet?

Central banks and unconventional green policy

by Alessandro Ferrari and Valerio Nispi Landi

Number 1320 - February 2021 
The papers published in the Temi di discussione series describe preliminary results and are made available to the public to encourage discussion and elicit comments.

The views expressed in the articles are those of the authors and do not involve the responsibility of the Bank.

Editorial Board: Federico Cingano, Marianna Riggi, Monica Andini, Audinga Baltrunaite, Marco Bottone, Davide Delle Monache, Sara Formai, Francesco Franceschi, Adriana Grasso, Salvatore lo Bello, Juho Taneli Makinen, Luca Metelli, Marco Savegnago.

Editorial Assistants: Alessandra Giammarco, Roberto Marano.

ISSN 1594-7939 (print)

ISSN 2281-3950 (online)

Printed by the Printing and Publishing Division of the Bank of Italy 


\title{
WHATEVER IT TAKES TO SAVE THE PLANET? CENTRAL BANKS AND UNCONVENTIONAL GREEN POLICY
}

\author{
by Alessandro Ferrari* and Valerio Nispi Landi*
}

\begin{abstract}
We study the effects of a temporary Green QE, defined as a policy that temporarily tilts the central bank's balance sheet toward green bonds, i.e. bonds issued by firms in nonpolluting sectors. To this end, we merge a standard DSGE framework with an environmental model in which detrimental emissions increase the stock of pollution. Imperfect substitutability between green and brown bonds is a necessary condition for the effectiveness of Green QE. While a temporary Green QE is an effective tool for mitigating detrimental emissions, it has limited effects in reducing the stock of pollution, if pollutants, e.g. $\mathrm{CO}_{2}$, stay in the atmosphere for a long time. The welfare gains of Green QE are positive but small. Welfare gains are larger if the flow of emissions negatively affects the utility of households.
\end{abstract}

JEL Classification: E52, E58, Q54.

Keywords: central bank, monetary policy, Quantitative Easing, climate change

DOI: $10.32057 / 0 . T D .2021 .1320$

\section{Contents}

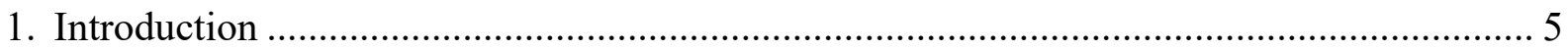

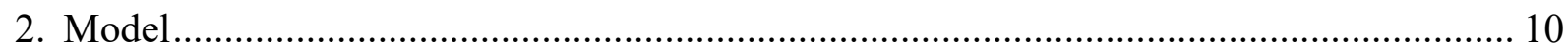

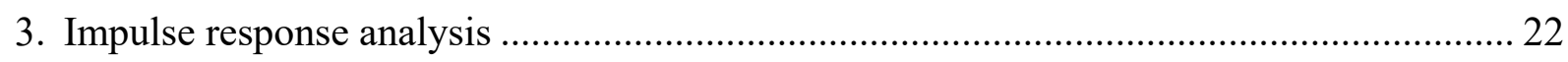

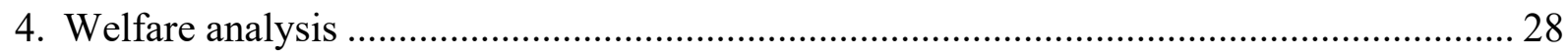

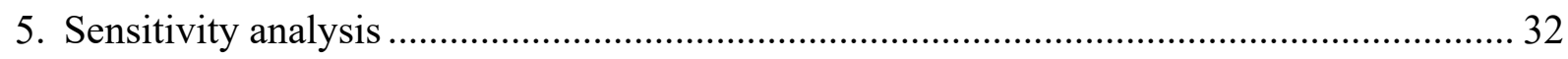

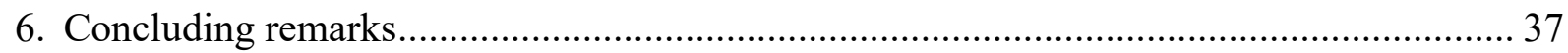

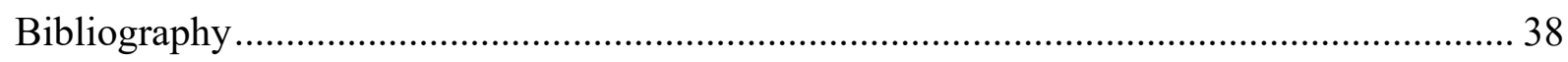

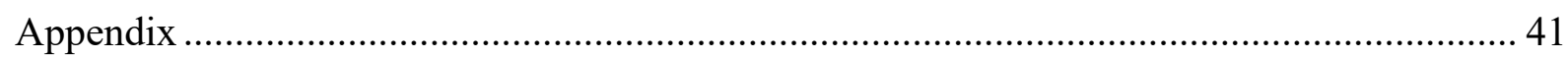

\footnotetext{
* Bank of Italy, Directorate General for Economics, Statistics and Research.
} 

"Through our strategy review, we will determine where and how the issue of climate change and the fight against climate change can actually have an impact on our policies"

— Christine Lagarde

\section{Introduction $^{1}$}

In the last few years the scientific community has been increasing its warnings on the fact that "planet Earth is facing climate emergency" (Ripple et al., 2017; Ripple et al., 2020). The warnings of scientists have been attracting interest among the public opinion, and several demonstrations have taken place all over the world, often led by influential environmental activists. Scientists argue that the climate crisis is closely linked to excessive consumption of the advanced economies, which feature the greatest percapita emissions of greenhouse gas. This fact establishes a challenging trade-off for policy makers, who have the hard task to mitigate the adverse consequences of climate change without jeopardizing economic growth.

Climate change is the standard example of a negative externality, which should be addressed by an appropriate Pigovian tax. ${ }^{2}$ However, climate change is not a challenge that can be solved in the short-term. As argued by Carney (2015), climate change is a "tragedy of the horizon", because its impact lies well beyond the horizon of most actors. While the political costs of enacting environmental regulation and raising ecofriendly taxes must be faced in the short term, the associated welfare and political gains are likely to emerge only in the medium-long term, suggesting that political economics arguments may play an important role. As an anecdotal example, the French Government was forced to postpone the increase in the eco-tax on fuel, after several protests by the so called "Yellow Vests". If governments cannot raise taxes to tackle climate change, independent institutions such as central banks may be better placed to face the climate change challenge.

The aim of this paper is to enrich the debate on the role of central banks in fighting climate change through the lens of a formal model. To this purpose, we merge the workhorse DSGE framework with an environmental model: in this setup, we study the

\footnotetext{
${ }^{1}$ We thank our discussant Barbara Annicchiarico for her useful feedback. We are also grateful to Katrin Assenmacher, Alessandro Cantelmo, Paola Di Casola, Gianluigi Ferrucci, Francesco Giovanardi, Peter Karadi, Filippo Natoli, Stefano Neri, Salvatore Nisticò, Massimiliano Pisani, Andrea Papetti, Francesco Paternò, Cosimo Petracchi, Luca Riva, Alessandro Secchi, Andrea Tiseno, seminar online participants at the ECB, Bank of Italy, and Brown University, and conference participants at the 19th Macroeconomic Dynamics Conference for their comments and suggestions. The opinions expressed in this paper are those of the authors and do not necessarily reflect the views of the Bank of Italy.

${ }^{2}$ For instance, this is the view by Rogoff (2019).
} 
macroeconomic and welfare consequences of the so called "Green Quantitative Easing" (Green QE), defined as a central bank's purchase of bonds issued by firms in non-polluting sectors.

In the last decade, DSGE models have been commonly used to analyze the effects of $\mathrm{QE}$, defined as an asset purchase program of the central bank targeted to public or private bonds (Curdia and Woodford, 2011; Gertler and Karadi, 2011; Chen et al., 2012; Gertler and Karadi, 2013; Burlon et al., 2018). DSGE models have been also used to study the effects of environmental policies. Heutel (2012), Annicchiarico and Di Dio (2015), and Barrage (2020) are applications of the benchmark environmental setup of Nordhaus (2008), which includes an economic and a geophysical sector. In these models, production increases the flow of $\mathrm{CO}_{2}$ emissions, which fuel the stock of atmospheric carbon (or, more generally, the stock of pollution). In turn, a higher atmospheric carbon reduces the total factor productivity of the economy: as highlighted by Nordhaus (2008), pollutants such as $\mathrm{CO}_{2}$ and other greenhouse gases are likely to affect the production possibilities of the world economy through their positive effects on global temperature. ${ }^{3}$ Our model is the result of merging the DSGE framework of Gertler and Karadi (2011), designed to study QE, with the environmental model of Heutel (2012), designed to study environmental policies over the business cycle.

In our model, we distinguish between two production sectors: the brown sector, whose production generates damaging emissions, and a green sector, whose production is not polluting. This assumption allows to distinguish between bonds issued by green firms (green bonds) and bonds issued by brown firms (brown bonds). Bonds can be bought by private banks and by the central bank. A leverage constraint prevents banks to fully exploit the arbitrage opportunity between bonds and deposits from households: in equilibrium, there is a spread between the bond and the deposit interest rate.

We define Green QE as a policy that tilts the central bank's balance sheet toward the green sector. We distinguish between two types of Green QE: a Green QE that does not change the size of central bank's balance sheet; a Green QE that increases the size of central bank's balance sheet. It is well known that QE can work only if Wallace Neutrality is broken. As Wallace (1981) points out, the equilibrium path of output and prices is independent from central bank's balance sheet policies, unless there is something special in central bank's intermediation. In our model, QE does affect production, because the central bank, as opposed to private banks, does not face leverage constraints. If the central bank temporarily expands its balance sheet by increasing holding of green and brown bonds, banks reduce their leverage, credit spread goes down, and output

\footnotetext{
${ }^{3}$ For example, higher temperature may damage agriculture and forestry, and it may cause coastal flooding by increasing the sea level.
} 
grows. This is the mechanism at the heart of Gertler and Karadi (2011). If green and brown bonds are perfect substitutes for banks, when the central bank temporarily tilts the portfolio composition to green bonds keeping the size of the balance sheet constant, production in both sectors is not affected. Without further assumptions, even in a model where QE works, this balance-sheet neutral Green QE is not able to affect neither total production nor damaging emissions. The intuition relies on a no-arbitrage condition. If green and brown bonds are perfect substitutes for banks, their returns must be identical as well. In this case, the portfolio rebalancing of the central bank determined by Green QE is fully offset by a rebalancing of private banks in the opposite direction. Under this scenario, Green QE only implies a transaction between private banks and the central bank, with no macroeconomic or environmental effect. ${ }^{4}$ As a result of the same intuition, a Green QE that increases the size of central bank's balance sheet has the same effects of a market-neutral QE.

In order to explore the role of Green QE, we make green and brown bonds imperfect substitutes. ${ }^{5}$ We do so by introducing a quadratic cost whenever a bank changes the composition of its portfolio with respect to the steady-state level. ${ }^{6}$ Under this hypothesis, the share of bank's green bonds out of bank's total assets is a positive function of the spread between green and brown bonds: the higher the interest rate paid by green bonds relatively to brown bonds, the more banks invest in the green sector.

Having a model suited to study Green QE, we perform four experiments.

In the first experiment, we simulate a temporary Green QE shock. When the central bank temporarily increases its share of green bonds, keeping constant total assets, the interest rate paid by green (brown) firms decrease (increase). Banks are not able to fully exploit the arbitrage opportunity, because changing the asset composition is costly: a spread between brown and green interest rates opens up. Green firms face a lower interest rate, increase capital and raise production. Brown firms face higher interest rate and cut production: detrimental emissions are lower and decrease the stock of atmospheric carbon. The production externality is reduced and total factor productivity increases. From a quantitative perspective, Green QE is effective in reducing detrimental emissions. However, the effects on the total stock of pollution and thus on TFP are negligible. Our calibration, that we borrow from Nordhaus (2008) and Heutel (2012), implies that

\footnotetext{
${ }^{4}$ Bonds are issued by firms in every period: when the central bank invests in corporate bonds, either it directly buys bonds from firms, or it buys bonds on the secondary markets from banks. The same holds for banks: they can either directly buy bonds from firms or they can buy bonds from the central bank.

${ }^{5}$ This assumption is consistent with the empirical evidence reported by Giovanardi et al. (2020), which show that the spread between green and conventional bonds react to ECB announcements regarding environmental policy.

${ }^{6}$ This friction is used extensively in DSGE models, in order to make different assets imperfect substitutes (see for instance Benigno, 2009 and Curdia and Woodford, 2011.)
} 
atmospheric carbon follows a highly persistent process: given that the Green QE shock is temporary, emissions are lower only in the short run, bringing about a tiny reduction in the stock of pollution. Moreover, the marginal TFP gain of reducing pollution is almost 0 close to the steady state: this results hinges on the small TFP loss caused by pollution in the model by Nordhaus (2008), if steady-state pollution is set to current values.

In our second experiment, we simulate an increase in central bank's total assets (a QE shock) comparing two different scenarios. In the first scenario, we assume that central bank's purchases respect market neutrality. In the second scenario, we assume that QE is entirely targeted to green bonds. We show that the difference between the two scenarios is quantitatively mild both for macroeconomic variables and pollution. In addition, even if QE is entirely targeted to green bonds, its expansionary effect also boosts brown production in the first periods, driving a slightly higher rise in pollution.

In the third experiment, we design a Taylor rule for Green QE, assuming that the fraction of central bank's green assets endogenously respond to brown production. We simulate a positive TFP shock, comparing the response of the economy with and without the Green QE rule. We find again that Green QE is able to mitigate emissions, but the quantitative impact on pollution is negligible.

In the fourth and final experiment, we assess the welfare implications and we show three additional results. First, we compute the constant tax on brown production that makes the steady state of the model equal to the steady-state of a social-planner economy. The tax is $0.4 \%$, reflecting the low steady state-state pollution cost in the baseline calibration: by increasing the cost of pollution, we get a much higher tax. We cannot do this exercise with Green QE, because as other monetary policy instruments, in our model Green QE has no effect in the steady state. Second, we compute numerically the constant tax that optimizes welfare in an economy hit by positive and negative TFP shocks. The optimal constant tax is in line with the previous exercise. Third, we compute numerically the parameter of the Green QE rule that maximizes welfare after a positive TFP shock. This parameter governs the elasticity of Green QE to brown production. We find that the central bank should aggressively respond to brown production, though net welfare gains are extremely small.

The main result of our study is that a temporary Green QE is able to affect detrimental emissions in the brown sector, but it has small effects on the stock of atmospheric carbon. The main reason is that climate change and pollution are structural problems, while a temporary Green QE is an instrument that plays a role along the business-cycle, as other monetary policy tools: a temporary Green QE struggles to affect a slow-moving variable such as the stock of atmospheric carbon, which stay in the atmosphere for a long time. Indeed, we also show that Green QE yields higher welfare gains if we increase the decay 
rate of pollution. Nevertheless, there are some important caveats that should be kept well in mind. We have modeled a temporary as opposed to a permanent Green QE: the latter could set the stage for a permanent lower size of the brown sector. Even if in most DSGE models monetary neutrality holds in the long run, we believe that the central bank may still be able to permanently affect the behavior of economic agents, through incentives and moral suasion to invest more in the green sector. Monetary policy could also induce green firms to invest more in R\&D: as far as R\&D investment increases long-run TFP, monetary policy may have a permanent positive effect on the green sector. Moreover, a temporary Green QE may still be useful along a transition from a steady state with high emissions to a steady state with low emissions. We leave these considerations to feature research.

We aim at building a bridge between two different streams of the literature. First, our paper fits in the literature studying the effectiveness of QE in DSGE models. This literature has flourished in the aftermath of the Great Recession, when central banks around the world hit the zero-lower bound and started to implement large-scale asset purchases. Curdia and Woodford (2011) compute central bank's optimal balance sheet policy in a New Keynesian model with two types of households (borrowers and savers). Gertler and Karadi (2011) and Gertler and Karadi (2013) analyze the macroeconomic effects and the desirability of the FED balance sheet's policy in a DSGE model augmented with a banking sector. In these three papers, central bank's lending to the private sector is an effective policy to reduce the credit spread. Chen et al. (2012) estimate a mediumscale DSGE model with financial market segmentation, finding that the second FED Large Scale Asset Purchase Program had very limited effects on output and inflation. Burlon et al. (2018) study the interaction between the ECB Asset Purchase Programme and macroprudential policy, in a large-scale model for the euro area.

Second, our paper fits in the literature studying climate-related issues in DSGE models. Fischer and Springborn (2011), Heutel (2012), and Angelopoulos et al. (2013) study environmental policies in an RBC model, while Annicchiarico and Di Dio (2015) analyze these policy tools in a model with nominal rigidities. Bartocci and Pisani (2013) assess the effects of taxing motor vehicle fuels for private transportation in the main EU countries. Golosov et al. (2014) derive a simple formula for the optimal carbon tax. Chan (2020) explores the interaction between standard macroeconomic policies (fiscal and monetary) with carbon taxation. Barrage (2020) studies the interaction of carbon taxes with other standard distortionary taxes. Giovanardi et al. (2020) analyze the effects of reducing the haircut applied by the central bank to green bonds that are used as collateral in refinancing operations. In these papers, the climate/pollution externality is an increasing function of total output: the externality either affects total factor 
productivity (as in Nordhaus, 2008), or enters directly the utility of households. The papers closest to our work are Dafermos et al. (2018) and Diluiso et al. (2020). Using a stock-flow-fund model, Dafermos et al. (2018) assess the financial and global warming implications of Green QE. Unlike Dafermos et al. (2018), we use a microfunded DSGE model to study Green QE. In a contemporaneous work, Diluiso et al. (2020) develop a DSGE model to study the financial stability implications of climate change and of the transition toward a green economy. In one experiment, they also study an expansion of central bank's balance sheets targeted to green assets, in response to a climate shock. Unlike Diluiso et al. (2020), we exclusively focus on Green QE and we crucially assume that banks cannot fully arbitrage green and brown bonds: this assumption is crucial for Green QE to affect the spread between green and brown interest rates.

The rest of the paper is organized as follows. Section 2 presents the model. In Section 3 we analyze the transmission channel of Green QE. In Section 4 we carry out a welfare analysis. In Section 5 we perform some robustness checks. Section 5 concludes.

\section{Model}

We merge the financial accelerator framework of Gertler and Karadi (2011) with the environmental model of Heutel (2012), which in turn is a simplified version of Nordhaus (2008). ${ }^{7}$ Unlike Gertler and Karadi (2011) and Heutel (2012), our model features two production sectors: a brown sector, which generates a pollution externality affecting total factor productivity; a green sector, which does not generate any externality. ${ }^{8}$ Two different sectors are crucial to distinguish between green bonds and brown bonds. Green and brown firms sell their goods to a continuum of intermediate firms. These firms operate in monopolistic competition and are subject to price-adjustment costs. A final good-firm combines the differentiated intermediate goods to produce a final good. The final is good is bought by households for consumption and by capital producers, which transform it in physical capital. Households can be either workers in green and brown firms, or bankers. Bankers, collect deposit from households and grant loans to green and brown firms. In what follows, we lay out the optimization problems of all the agents of the model. We leave the full list of equations to the Appendix.

\footnotetext{
${ }^{7}$ The major difference between the two environmental models is the following. In Heutel (2012) all the variables, including pollution, revert in the long-run in the steady state: this model is appropriate for cycle analysis. Nordhaus (2008) is a growth model with a steady growth path for pollution: this model is better suited for analysis of structural policies and their long-term impact.

${ }^{8}$ In Heutel (2012) all firms generate the pollution externality. In our model, only brown firms pollute.
} 


\subsection{Households}

There is a continuum of households of measure unity. In any period, a fraction $1-f$ of households are workers, a fraction $f$ are bankers. Every banker stays banker in the next period with probability $\chi$ : in every period $(1-\chi) f$ bankers become worker. It is assumed that $(1-\chi) f$ workers randomly become bankers and the proportion remains unchanged. Each banker manages a bank and transfers profits to households. Different households completely share idiosyncratic risk: this assumption allows to use the representative household framework.

The representative household solves the following optimization problem:

$$
\begin{array}{r}
\max _{\left\{c_{t}, h_{t}, d_{t}\right\}_{t=0}^{\infty}} \mathbb{E}_{0} \sum_{t=0}^{\infty} \beta^{t}\left(\frac{c_{t}^{1-\sigma}}{1-\sigma}-\frac{h_{t}^{1+\varphi}}{1+\varphi}\right) \\
\text { s.t. } c_{t}+d_{H t}=\frac{r_{t-1}}{\pi_{t}} d_{H t-1}+w_{t} h_{t}-t_{t}+\Gamma_{t},
\end{array}
$$

where $c_{t}$ denotes consumption of the final good; $h_{t}$ denotes hours worked; $d_{H t}$ is the sum of bank deposits $d_{t}$ and public bonds $d_{P t}$ : both assets are expressed in real terms and yield a nominal interest rate $r_{t} ; w_{t}$ is hourly real wage; $\pi_{t}$ is CPI gross inflation rate; $t_{t}$ denote lump-sum taxes; $\Gamma_{t}$ are profits from ownership of firms and net transfers from banks. First-order conditions read:

$$
\begin{aligned}
h_{t}^{\varphi} c_{t}^{\sigma} & =w_{t} \\
c_{t}^{-\sigma} & =\beta \mathbb{E}_{t}\left(c_{t+1}^{-\sigma} \frac{r_{t}}{\pi_{t+1}}\right) .
\end{aligned}
$$

\section{$2.2 \quad$ Final-good firms}

The representative final-good firm uses the following CES aggregator to produce the final good $y_{t}$ :

$$
y_{t}=\left[\int_{0}^{1} y_{t}(i)^{\frac{\varepsilon-1}{\varepsilon}} d i\right]^{\frac{\varepsilon}{\varepsilon-1}},
$$

where $y_{t}(i)$ is an intermediate good produced by intermediate firm $i$, whose price is $p_{t}(i)$. The problem of the final-good firm is the following:

$$
\begin{gathered}
\max _{y_{t},\left\{y_{t}(i)\right\}_{i \in[0,1]}} p_{t} y_{t}-\int_{0}^{1} p_{t}(i) y_{t}(i) d i \\
\text { s.t } y_{t}=\left[\int_{0}^{1} y_{t}(i)^{\frac{\varepsilon-1}{\varepsilon}} d i\right]^{\frac{\varepsilon}{\varepsilon-1}},
\end{gathered}
$$


where $p_{t}$ is the CPI. This problem yields the following demand function $\forall i$ :

$$
y_{t}(i)=y_{t}\left(\frac{p_{t}(i)}{p_{t}}\right)^{-\varepsilon}
$$

\subsection{Intermediate-good firms}

There is a continuum of firms indexed by $i$ producing a differentiated input using the following linear function:

$$
y_{t}(i)=y_{t}^{I}(i)
$$

where $y_{t}^{I}$ is a CES aggregator of green production $y_{t}^{G}$ and brown production $y_{t}^{B}$ :

$$
y_{t}^{I}(i)=\left[(1-\zeta)^{\frac{1}{\xi}}\left(y_{t}^{G}(i)\right)^{\frac{\xi-1}{\xi}}+\zeta^{\frac{1}{\xi}}\left(y_{t}^{B}(i)\right)^{\frac{\xi-1}{\xi}}\right]^{\frac{\xi}{\xi-1}} .
$$

In order to choose the optimal input combination, intermediate firm $i$ solves the following intratemporal problem:

$$
\begin{array}{r}
\max _{y_{t}^{B}, y_{t}^{G}}\left[(1-\zeta)^{\frac{1}{\xi}}\left(y_{t}^{G}(i)\right)^{\frac{\xi-1}{\xi}}+\zeta^{\frac{1}{\xi}}\left(y_{t}^{B}(i)\right)^{\frac{\xi-1}{\xi}}\right]^{\frac{\xi}{\xi-1}} \\
p_{t}^{G} y_{t}^{G}(i)+p_{t}^{B} y_{t}^{B}(i)=Y_{t}(i),
\end{array}
$$

where $Y_{t}(i)$ is a given level of production; $p_{t}^{G}$ and $p_{t}^{B}$ are the price of green and brown production respectively, both expressed relatively to the CPI. The problem yields the following demand functions:

$$
\begin{aligned}
& y_{t}^{G}(i)=(1-\zeta)\left(\frac{p_{t}^{G}}{p_{t}^{I}}\right)^{-\xi} y_{t}^{I}(i) \\
& y_{t}^{B}(i)=\zeta\left(\frac{p_{t}^{B}}{p_{t}^{I}}\right)^{-\xi} y_{t}^{I}(i),
\end{aligned}
$$

where $p_{t}^{I}=\left[(1-\zeta)\left(p_{t}^{G}\right)^{1-\xi}+\zeta\left(p_{t}^{B}\right)^{1-\xi}\right]^{\frac{1}{1-\xi}}$ is the real marginal cost of the firm.

Firms operate in monopolistic competition, so they set prices subject to the demand of the final good firm (4). Firm $i$ pays quadratic adjustment costs $A C_{t}(i)$ in nominal terms, whenever it adjusts the growth of its price $p_{t}(i)$ with respect to the benchmark level $\bar{\pi}$ :

$$
A C_{t}(i)=\frac{\kappa_{P}}{2}\left(\frac{p_{t}(i)}{p_{t-1}(i)}-\bar{\pi}\right)^{2} p_{t} y_{t}
$$


Firm $i$ 's intertemporal maximization problem reads:

$$
\max _{\left\{p_{t}(i)\right\}_{t=0}^{\infty}} \mathbb{E}_{0}\left\{\sum_{t=0}^{\infty} \beta^{t} \frac{\lambda_{t}}{\lambda_{0}}\left[\left(\frac{p_{t}(i)}{p_{t}}\right)^{-\varepsilon}\left(\frac{p_{t}(i)}{p_{t}}-p_{t}^{I}\right) y_{t}-\frac{\kappa_{P}}{2}\left(\frac{p_{t}(i)}{p_{t-1}(i)}-\bar{\pi}\right)^{2} y_{t}\right]\right\},
$$

where $\lambda_{t}$ is the marginal utility of households. In a symmetric equilibrium, this problem yields the standard Phillips Curve:

$$
\pi_{t}\left(\pi_{t}-\bar{\pi}\right)=\beta \mathbb{E}_{t}\left[\frac{\lambda_{t+1}}{\lambda_{t}} \pi_{t+1}\left(\pi_{t+1}-\bar{\pi}\right) \frac{y_{t+1}}{y_{t}}\right]+\frac{\varepsilon}{\kappa_{P}}\left(p_{t}^{I}-\frac{\varepsilon-1}{\varepsilon}\right)
$$

\subsection{Green and brown firms}

Green and brown firms produce an output good that is used as an input by intermediate firms. Green firms use the following function to produce $y_{t}^{G}$ :

$$
y_{t}^{G}=A_{t}\left(k_{t-1}^{G}\right)^{\alpha} h_{t}^{G(1-\alpha)}
$$

where $k_{t}^{G}$ and $h_{t}^{G}$ are capital and labor used in the green sector; $A_{t}$ is total factor productivity, which is endogenous. We explain in detail what drives total factor productivity in Section 2.7. Green firms issue bonds $b_{t}^{G}$ to finance capital expenditure:

$$
b_{t}^{G}=q_{t} k_{t}^{G},
$$

where $q_{t}$ is the price of the capital good. The bond is expressed in real terms and pay a real interest rate $r_{t}^{G}$. Green firms buy capital from capital producers, which in turn buy back non-depreciated capital from green firms. In period $t$, profits $\Gamma_{t}^{G}$ of green firms are given by:

$$
\Gamma_{t}^{G}=p_{t}^{G} y_{t}^{G}-w_{t} h_{t}^{G}-r_{k t}^{G} k_{t-1}^{G}
$$

where

$$
r_{k t}^{G} \equiv\left[r_{t}^{G} q_{t-1}-(1-\delta) q_{t}\right]
$$

is the rental rate of capital for green firms. First order conditions for green firms read:

$$
\begin{aligned}
w_{t} h_{t}^{G} & =(1-\alpha) p_{t}^{G} y_{t}^{G} \\
r_{k t}^{G} k_{t-1}^{G} & =\alpha p_{t}^{G} y_{t}^{G} .
\end{aligned}
$$


The brown sector is modeled analogously and it comprises the following equations:

$$
\begin{aligned}
y_{t}^{B} & =A_{t}\left(k_{t-1}^{B}\right)^{\alpha} h_{t}^{B(1-\alpha)} \\
w_{t} h_{t}^{B} & =(1-\alpha) p_{t}^{B} y_{t}^{B} \\
r_{k t}^{B} k_{t-1}^{B} & =\alpha p_{t}^{B} y_{t}^{B} \\
b_{t}^{B} & =q_{t} k_{t}^{B} \\
r_{k t}^{B} & =r_{t}^{B} q_{t-1}-(1-\delta) q_{t} .
\end{aligned}
$$

\subsection{Capital producers}

Capital producers buy output produced by final-good firms and non-depreciated capital from intermediate firms, in order to produce physical capital. Capital is then purchased by green and brown firms. Capital producers solve the following problem:

$$
\begin{aligned}
& \max _{\left\{i_{t}, k_{t}\right\}_{t=0}^{\infty}} \mathbb{E}_{0}\left\{\sum_{t=0}^{\infty} \beta^{t} \frac{\lambda_{t}}{\lambda_{0}}\left[q_{t} k_{t}-(1-\delta) q_{t} k_{t-1}-i_{t}\right]\right\} \\
& \text { s.t. } k_{t}=(1-\delta) k_{t-1}+\left[1-\frac{\kappa_{I}}{2}\left(\frac{i_{t}}{i_{t-1}}-1\right)^{2}\right] i_{t},
\end{aligned}
$$

where $k_{t}$ is aggregate capital in the economy and $i_{t}$ denotes investment. The first order condition reads:

$q_{t}\left\{1-\frac{\kappa_{I}}{2}\left(\frac{i_{t}}{i_{t-1}}-1\right)^{2}-\kappa_{I} \frac{i_{t}}{i_{t-1}}\left(\frac{i_{t}}{i_{t-1}}-1\right)\right\}+\beta \mathbb{E}_{t}\left[\frac{\lambda_{t+1}}{\lambda_{t}} q_{t+1}\left(\frac{i_{t+1}}{i_{t}}\right)^{2} \kappa_{I}\left(\frac{i_{t+1}}{i_{t}}-1\right)\right]=1$

\subsection{Banks}

There is a continuum of banks indexed by $j$. The balance sheet of bank $j$ is given by:

$$
b_{F t}^{B}(j)+b_{F t}^{G}(j)=n_{t}(j)+d_{t}(j),
$$


where $b_{F t}^{B}(j)$ and $b_{F t}^{G}(j)$ are green and brown bonds purchased by bank $j ; n_{t}(j)$ is bank $j$ 's net worth, which accumulates trough profits:

$$
\begin{aligned}
n_{t}(j) & =r_{t}^{B} b_{F t-1}^{B}(j)+r_{t}^{G} b_{F t-1}^{G}(j)-\frac{r_{t-1}}{\pi_{t}} d_{t-1}(j)+ \\
& -\frac{\kappa_{F G}}{2} n_{t-1}(j)\left(\frac{b_{F t-1}^{G}(j)}{b_{F t-1}(j)}-b^{*}\right)^{2},
\end{aligned}
$$

where $b_{F t}(j) \equiv b_{F t}^{B}(j)+b_{F t}^{G}(j)$ denotes total assets of bank $j$. The last term in $(22)$ is a quadratic cost faced by the bank when the fraction of green bonds out of total bonds is different from the steady-state level $b^{*}$. This friction is a reduced-form device to prevent free arbitrage between green and brown bonds. We show that whenever $\kappa_{F G}>0$, Green QE can affect green and brown production.

Let $\beta^{i} \Lambda_{t, t+i}$ be the stochastic discount factor applying in $t$ to earnings in $t+i$, where $\Lambda_{t, t+i} \equiv \frac{\lambda_{t+i}}{\lambda_{t}}$. With probability $(1-\chi)$ banker $j$ exits the market getting $n_{t+1}(j)$ at the beginning of period $t+1$ : these resources are transferred to households. With probability $\chi$, banker $j$ continues the activity, getting the continuation value. The value of bank $j$ is defined as follows:

$$
V_{j t}\left(n_{t}(j)\right)=\max \mathbb{E}_{t}\left[\sum_{i=0}^{\infty}(1-\chi) \chi^{i} \beta^{i+1} \Lambda_{t, t+1+i} n_{t+1+i}(j)\right] .
$$

Following Gertler and Karadi (2011), we assume that in every period bankers can divert a fraction $\theta$ of available funds. If they do so, depositors can recover the remaining fraction of the assets. Depositors are willing to lend to bankers if and only if the value of the bank is not lower than the fraction of divertable funds:

$$
V_{j t}\left(n_{t}(j)\right) \geq \theta b_{F t}(j)
$$

This friction prevents banks to increase assets indefinitely, by exploiting the spread between lending and borrowing rate. Crucially, Gertler and Karadi (2011) show that this friction makes QE work. In Section 3.1, we argue that this friction is neither necessary nor sufficient to make Green QE work. We still keep the friction because it makes sense for us studying Green QE in a framework typically used to analyze QE.

We consider an equilibrium in which (24) is binding and every bank chooses the same leverage ratios. The problem of banks is to maximize the value function (23) subject to (22) and (24). The first order conditions for the bank read: 


$$
\begin{gathered}
l_{t}=\frac{\mathbb{E}_{t}\left\{\beta \frac{\lambda_{t+1}}{\lambda_{t}} \nu_{t+1}\left[\left(r_{t+1}^{G}-r_{t+1}^{B}\right) l_{t}^{G}+\frac{r_{t}}{\pi_{t+1}}-\frac{\kappa_{F G}}{2}\left(\frac{l_{t}^{G}}{l_{t}}-b^{*}\right)^{2}\right]\right\}}{\theta-\mathbb{E}_{t}\left\{\beta \frac{\lambda_{t+1}}{\lambda_{t}} \nu_{t+1}\left(r_{t+1}^{B}-\frac{r_{t}}{\pi_{t+1}}\right)\right\}} \\
\frac{\kappa_{F G}}{l_{t}}\left(\frac{l_{t}^{G}}{l_{t}}-b^{*}\right)=\frac{\mathbb{E}_{t}\left\{\beta \frac{\lambda_{t+1}}{\lambda_{t}} \nu_{t+1}\left(r_{t+1}^{G}-r_{t+1}^{B}\right)\right\}}{\mathbb{E}_{t}\left\{\beta \frac{\lambda_{t+1}}{\lambda_{t}} \nu_{t+1}\right\}},
\end{gathered}
$$

where $l_{t} \equiv \frac{b_{F t}}{n_{t}}$ and $l_{t}^{G} \equiv \frac{b_{F t}^{G}}{n_{t}}$ are the bank's total leverage and green leverage ratio respectively; $\nu_{t}$ can be interpreted as the bank's discount factor:

$$
\begin{aligned}
& \nu_{t}=(1-\chi)+ \\
& +\chi \beta \mathbb{E}_{t}\left\{\frac{\lambda_{t+1}}{\lambda_{t}} \nu_{t+1}\left[\left(r_{t+1}^{G}-r_{t+1}^{B}\right) l_{t}^{G}+\left(r_{t+1}^{B}-\frac{r_{t}}{\pi_{t+1}}\right) l_{t}+\frac{r_{t}}{\pi_{t+1}}-\frac{\kappa_{F G}}{2}\left(\frac{l_{t}^{G}}{l_{t}}-b^{*}\right)^{2}\right]\right\} .
\end{aligned}
$$

Equation (26) is new compared to the literature. If $\kappa_{F G}=0$, the spread between green and brown bonds is zero in expectation: equation (25) would collapse to the expression in Gertler and Karadi (2011). If $\kappa_{F G}>0$, arbitrage between green and brown bonds is not perfect: an increase in the spread between green and brown bonds induces banks to replace brown bonds with green bonds. Given that changing asset composition is costly, arbitrage does not necessarily brings back the spread to zero. A first-order approximation of equation (26) yields:

$$
\left(\tilde{b}_{F t}^{G}-\tilde{b}_{F t}\right)=\eta \mathbb{E}_{t}\left(r_{t+1}^{G}-r_{t+1}^{B}\right),
$$

where $\eta \equiv \frac{l}{\kappa_{F G}(1-\zeta)}$, variables with a tilde are expressed in percentage deviations from steady state, variables without time subscript denote the steady-state value. Parameter $\eta$ gives the percentage increase in the share of green assets out of total banking assets after a 100 basis points increase in the expected spread between green and brown bonds.

Aggregate net worth can be split between net worth of new bankers $n_{y t}$ and net worth of old bankers $n_{o t}$ :

$$
n_{t}=n_{o t}+n_{y t}
$$

Since a fraction $\chi$ of bankers in period $t-1$ survive until period $t$, it holds:

$$
n_{o t}=\chi\left[\left(r_{t}^{G}-r_{t}^{B}\right) l_{t-1}^{G}+\left(r_{t}^{B}-\frac{r_{t-1}}{\pi_{t}}\right) l_{t-1}+\frac{r_{t-1}}{\pi_{t}}-\frac{\kappa_{F G}}{2}\left(\frac{l_{t-1}^{G}}{l_{t-1}}-b^{*}\right)^{2}\right] n_{t-1}
$$


We assume that households transfer a share of assets of exiting bankers $\frac{\iota}{1-\chi}$ to new bankers, in order to start business:

$$
n_{y t}=\iota b_{F t}
$$

Using (29) and (30) we can derive an expression for the evolution of aggregate bank net worth:

$$
n_{t}=\chi\left[\left(r_{t}^{G}-r_{t}^{B}\right) l_{t-1}^{G}+\left(r_{t}^{B}-\frac{r_{t-1}}{\pi_{t}}\right) l_{t-1}+\frac{r_{t-1}}{\pi_{t}}-\frac{\kappa_{F G}}{2}\left(\frac{l_{t-1}^{G}}{l_{t-1}}-b^{*}\right)^{2}\right] n_{t-1}+\iota b_{F t} .
$$

\subsection{Pollution externality}

In order to capture the production effects on climate change, we adopt the setup in Heutel (2012), which merges the baseline RBC model with a simplified version of Nordhaus (2008). ${ }^{9}$ In the last version of the Dynamic Integrated model of Climate and the Economy (DICE) by William Nordhaus, ${ }^{10}$ the geophysical sector is linked to the economy as follows. Industrial $\mathrm{CO}_{2}$ emissions are an increasing function of production. Higher emissions increase carbon in the atmosphere, which is also fueled by carbon in the oceans and exogenous non-industrial emissions. Higher values of atmospheric carbon raise the mean surface temperature, which in turn reduces total factor productivity. In the DICE model, the pollution externality affects the economy only through TFP. As in Angelopoulos et al. (2013) and Barrage (2020), pollution can directly affect the utility function of households. As argued by Nordhaus (2008) and Heutel (2012), a utility externality could be more appropriate for conventional pollutants that directly affect health. Instead, $\mathrm{CO}_{2}$ and other greenhouse gases are more likely to affect productivity of physical capital and labor inputs. We consider a utility cost of pollution in Section 5.1

Following Nordhaus (2008), we assume that total factor productivity in the green and brown sectors is given by the following expression:

$$
A_{t}=\left(1-D_{t}\left(x_{t}\right)\right) a_{t}
$$

where $a_{t}$ is the exogenous component of TFP and follows an autoregressive process:

$$
\log \left(a_{t}\right)=\left(1-\rho_{a}\right) \log (\bar{a})+\rho_{a} \log \left(a_{t-1}\right)+v_{t}^{a}
$$

\footnotetext{
${ }^{9}$ Heutel's model has been used in other papers to study the interaction between economic policies and climate. For instance, Annicchiarico and Di Dio (2015) and Chan (2020) augment Heutel's framework with New Keynesian nominal rigidities.

${ }^{10}$ Available at https://sites.google.com/site/williamdnordhaus/dice-rice.
} 
and $v_{t}^{a} \sim N\left(0, \sigma_{a}^{2}\right)$ is a technology shock. $D_{t}\left(x_{t}\right)$ is the damage function, which is increasing in atmospheric carbon (pollution) $x_{t}$. We model the damage function as in Heutel (2012):

$$
D_{t}=d_{0}+d_{1} x_{t}+d_{2} x_{t}^{2} .
$$

Compared to the DICE model, in Heutel (2012) (and in our setting), the output damage is a function of atmospheric carbon. In the DICE model, the output damage is a function of the mean surface temperature, which in turn depends on atmospheric carbon. Atmospheric carbon is a stock variable that is fueled by carbon emissions in the domestic economy $\left(e_{t}\right)$ and in the rest of the world $\left(e^{r o w}\right)$ :

$$
x_{t}=\left(1-\delta_{x}\right) x_{t-1}+e_{t}+e^{r o w} .
$$

Emissions are an increasing and concave function of brown production, as in Heutel $(2012):^{11}$

$$
e_{t}=\left(y_{t}^{B}\right)^{1-\psi}
$$

\subsection{Policy}

We treat the central bank and the government as a single entity. As before, variables without time subscript denote the steady-state level. We assume that investment in private assets by the public sector is financed through public bonds $d_{P t}$ :

$$
b_{P t}^{G}+b_{P t}^{B}=d_{P t},
$$

where $b_{P t}^{G}$ and $b_{P t}^{B}$ are green and brown bonds held by the public sector. A constant public consumption $g$ is financed through lump-sum taxes $t_{t}$ and intermediation profits:

$$
g=t_{t}+\left(r_{t}^{G}-\frac{r_{t-1}}{\pi_{t}}\right) b_{P t-1}^{G}+\left(r_{t}^{B}-\frac{r_{t-1}}{\pi_{t}}\right) b_{P t-1}^{B} .
$$

The public sector has three independent instruments that can be targeted to reach different objectives and that can potentially be in conflict. The first one is the nominal interest rate, set according to a standard Taylor rule:

$$
\frac{r_{t}}{r}=\left(\frac{r_{t-1}}{r}\right)^{\rho_{r}}\left[\left(\frac{\pi_{t}}{\bar{\pi}}\right)^{\phi_{\pi}}\left(\frac{y_{t}}{y}\right)^{\phi_{y}}\right]^{1-\rho_{r}},
$$

\footnotetext{
${ }^{11}$ Unlike Heutel (2012), we abstract from abatement technologies that can reduce the output loss from emissions.
} 
where $\bar{\pi}$ is the inflation target. The second instrument is $\mu_{t} \equiv \frac{b_{P t}}{b_{t}}$, the share of bonds held by the public sector, where $b_{t} \equiv b_{t}^{G}+b_{t}^{B}$ is the total amount of corporate bonds and $b_{P t} \equiv b_{P t}^{G}+b_{P t}^{B}$ is the total amount of bonds held by the public sector. We assume a Taylor rule for $\mu_{t}$, which can be interpreted as QE policy:

$$
\frac{\mu_{t}}{\bar{\mu}}=\left(\frac{\mu_{t-1}}{\bar{\mu}}\right)^{\rho_{\mu}}\left[\left(\frac{s p_{t}^{G}}{s p}\right)^{\phi_{\mu}}\left(\frac{s p_{t}^{B}}{s p}\right)^{\phi_{\mu}}\right]^{1-\rho_{\mu}} \exp \left(v_{t}^{q e}\right)
$$

where $\bar{\mu}$ is the QE target and $s p_{t}^{G}$ and $s p_{t}^{B}$ are credit spreads over the risk-free interest rate:

$$
\begin{aligned}
& s p_{t}^{G}=\mathbb{E}_{t}\left[r_{t+1}^{G}-\frac{r_{t}}{\pi_{t+1}}\right] \\
& s p_{t}^{B}=\mathbb{E}_{t}\left[r_{t+1}^{B}-\frac{r_{t}}{\pi_{t+1}}\right],
\end{aligned}
$$

and $v_{t}^{q e} \sim N\left(0, \sigma_{q e}^{2}\right)$ is a QE shock. As in Gertler and Karadi (2011), the rule targets the financial friction of the banking sector, i.e. the spread between lending and deposit rates: in this model bank can invest in two assets, therefore there exist two credit spreads.

The third instrument is Green QE. Define $\mu_{t}^{G} \equiv \frac{b_{P t}^{G}}{b_{P t}}$ as the share of green bonds held by the public sector. Green $\mathrm{QE}$ is set according to the following rule:

$$
\frac{\mu_{t}^{G}}{\bar{\mu}^{G}}=\left(\frac{\mu_{t-1}^{G}}{\bar{\mu}^{G}}\right)^{\rho_{G}}\left[\left(\frac{y_{B t}}{y_{B}}\right)^{\phi_{G}}\right]^{1-\rho_{G}} \exp \left(v_{t}^{g q e}\right),
$$

where $\bar{\mu}^{G}$ is the Green QE target and $v_{t}^{q e} \sim N\left(0, \sigma_{q e}^{2}\right)$ is a Green QE shock. The rule responds to the negative externality generated by the brown sector: when brown production is high relatively to the steady state, the public sector buys green bonds and sell brown bonds.

\subsection{Market clearing}

To close the model, we impose clearing in capital, labor, bond, and good markets. Clearing in capital and labor markets read:

$$
\begin{aligned}
& k_{t}=k_{t}^{G}+k_{t}^{B} \\
& h_{t}=h_{t}^{G}+h_{t}^{B} .
\end{aligned}
$$


Clearing in the bond market:

$$
\begin{aligned}
& b_{t}^{G}=b_{F t}^{G}+b_{F t}^{G} \\
& b_{t}^{B}=b_{F t}^{B}+b_{P t}^{B} .
\end{aligned}
$$

Clearing in the good market:

$$
y_{t}=c_{t}+i_{t}+g+\frac{\kappa_{P}}{2}\left(\pi_{t}-\bar{\pi}\right)^{2} y_{t}+\frac{\kappa_{F G} n_{t-1}}{2}\left(\frac{l_{t-1}^{G}}{l_{t-1}}-b^{*}\right)^{2} .
$$

\subsection{Calibration}

The model is calibrated at the quarterly frequency. We calibrate the parameters common in the New Keynesian literature to standard values. The parameters of the banking sector are calibrated following Gertler and Karadi (2011). The parameters of the environmental block are calibrated following Heutel (2012). Both these papers are calibrated to the US. Unlike Heutel (2012), we set the steady-state value of $x$ to 867 gigatons of atmospheric carbon, the value observed in 2018. ${ }^{12}$ This implies a steady-state output loss of $0.7 \%$. To match the steady state of $x$, we calibrate the weight of brown output $\zeta$ in the production function to $0.15 .^{13}$

Some parameters are specific to our model. We assume that the production function of intermediate firms is a Cobb-Douglas in $y_{B}$ and $y_{G}$ : this implies $\xi=1$. We set the steady-state share of bonds held by the central bank to 0.1. We assume that the steadystate asset composition of the central bank reflects market composition: this implies $\mu_{G}=0.85 .{ }^{14}$ We assume that QE and Green QE rules have same persistence of the monetary policy rule. In the baseline scenario, we set the response of QE and Green QE to their target variables to 0 . An important parameter is the value of the adjustment cost of the banking sector, $\kappa_{F G}$, which measures the costs of arbitraging between green and brown bonds. The main message of our paper is that Green QE has small effects: to be conservative, we set this parameter to a high value, in order to maximize the potential effects of Green QE. Specifically, we assume that a reduction of 100 basis points in the spread between green and brown bonds leads banks to reduce green bonds by $10 \%$ (keeping constant total bonds): we set $\kappa_{F G}=0.48$ in order to have $\eta=10$. This arbitrage opportunity is in the higher end of estimates found in the literature. ${ }^{15}$ In some

\footnotetext{
${ }^{12}$ Heutel sets $x$ to 800 , the value observed in 2005 .

${ }^{13}$ In Section 5.2 we try with a relatively high value for $\zeta$.

${ }^{14}$ In Section 5.2 we choose a a relatively high value for $\zeta$, which implies a lower value for $\mu_{G}$

${ }^{15}$ Chen et al. (2012) estimate the elasticity of the amount of long-term bonds to the spread between long- and short-term bonds: they find a value much lower than the value used in our model. In the open-economy literature, the parameter governing the arbitrage between domestic and foreign bond is
} 
experiments, we set $\eta=0$ (infinite adjustment costs) for illustrative purposes.

\begin{tabular}{|c|c|c|c|}
\hline Parameter & Description & Value & Notes \\
\hline $\bar{\beta}$ & Discount factor & 0.99 & \\
\hline$\sigma$ & Inverse of EIS & 2 & \\
\hline$\varphi$ & Inverse of Frisch elasticity & 1 & \\
\hline$\varepsilon$ & Elas. of subst. differentiated goods & 6 & \\
\hline$\alpha$ & Share of capital in production & 0.33 & \\
\hline$\kappa_{P}$ & Price adjustment costs & 26.8638 & Price duration of $3 / 4$ in Calvo \\
\hline$\delta$ & Depreciation rate & $2.5 \%$ & \\
\hline$\zeta$ & Weight of brown good & 0.1485 & To get $x=867$ \\
\hline$\xi$ & Elas. of subst. brown-green good & 1 & \\
\hline$\kappa_{I}$ & Investment adjustment cost & 2.48 & Christiano et al. (2005) \\
\hline$\theta$ & Divertable proportion of assets & 0.3847 & \\
\hline$\chi$ & Bank survival probability & 0.972 & \\
\hline$\iota$ & Wealth for new banks & 0.0021 & \\
\hline$\kappa_{F G}$ & Bank adj. cost & 0.4708 & To get $\eta=10$ \\
\hline$d_{0}$ & Constant in damage function & 0.0014 & \\
\hline$d_{1}$ & Linear term in damage function & $-6.6722 \times 10^{-6}$ & \\
\hline$d_{2}$ & Quadratic term in damage function & $1.4647 \times 10^{-8}$ & \\
\hline$\psi$ & Convexity of emission function & 0.304 & \\
\hline$\delta_{x}$ & Pollution depreciation & 0.0021 & \\
\hline$e^{\text {row }}$ & Emissions in the rest of the world & 1.3653 & To get $e^{r o w} / e=3$ \\
\hline$b^{*}$ & SS fraction of bank's green bonds & 0.8515 & \\
\hline$\pi$ & SS inflation & 1.005 & \\
\hline$\mu, \mu_{G}$ & SS QE and GQE & $0.1,0.8515$ & \\
\hline$g$ & Public spending & 0.2856 & To get $g / y=0.2$ \\
\hline$\phi_{\pi}, \phi_{y}$ & Taylor rule coefficients & $1.5,0$ & \\
\hline$\phi_{\mu}, \phi_{G}$ & QE and GQE coefficients & 0 & \\
\hline$\rho_{r}, \rho_{\mu}, \rho_{G}$ & Inertia of rules & 0.8 & \\
\hline$\rho_{a}$ & Persistence of shocks & 0.9 & \\
\hline
\end{tabular}

Table 1: Calibrated parameters.

typically calibrated to very small values (Benigno, 2009). 


\section{Impulse Response Analysis}

In this section we simulate three transitory shocks: a Green QE shock, a QE shock, and a TFP shock, considering several scenarios. Impulse response functions are obtained by solving the first-order approximation of the model around the deterministic steady state.

Another interesting analysis could be studying the steady-state effects of Green QE (i.e. modeling a permanent shift in the share of green bonds held by the central bank), as opposed to temporary shocks. Our setup does not allow to study permanent effects of monetary policy, both conventional and unconventional: as other standard DSGE models, the steady state is independent from monetary policy variables. However, there could be potential channels through which Green QE may have structural effects: we leave the study of these channels to future research. ${ }^{16}$

\subsection{When Green QE is effective}

We simulate the effects of a $5 \%$ positive and temporary Green QE shock $\left(v_{t}^{g q e}=0.05\right)$. The size of central bank's balance sheet is kept at the steady state $\mu$, meaning that the investment in green bonds is entirely financed through a reduction in brown bonds. The increase in central bank's green bond is persistent but not permanent, as specified by equation (43). We plot the impulse response functions for three different values of $\eta$ : $\infty$ (blue solid line, Figure 1), 10 (red dotted line, Figure 1), 0 (black dashed line, Figure 1). If $\eta \rightarrow \infty$, banks do not pay adjustment costs when they change their asset composition $\left(\kappa_{F G}=0\right)$ : green and brown bonds are perfect substitutes, the central bank is not able to affect the interest rates on these bonds. The increase in green bonds held by the central bank is fully offset by the reduction of green bonds held by private banks. The irrelevance of Green QE when green and brown bonds are perfect substitutes occurs even in a model where QE is able to affect the real economy.

If green and brown bonds are not perfect substitutes, Green QE does have an effect on macroeconomic and environmental variables. ${ }^{17}$ The increase in green bonds held by the central bank reduces the interest rate paid by green firms: the spread between the interest rate on green bonds and deposits decreases; the spread between interest rate on brown bonds and deposit increases. Even if brown bonds pay a higher interest rate, banks do

\footnotetext{
${ }^{16}$ The central bank may induce the private sector to invest more in the green sector through moral suasion. Moreover, conventional and unconventional monetary policy may also ave long-run effects, if they are able to affect, also temporarily, investment in R\&D.

${ }^{17}$ The assumption of imperfect substitutability is sufficient to make Green QE work: even in a model with frictionless financial markets where a market-neutral QE does not have any effects, assuming imperfect substitution between green and brown bonds allows Green QE to affect the economy.
} 
not fully exploit the arbitrage opportunity, because changing asset composition is costly. Capital expenses are lower for green firms, which rent more capital and produce more. The opposite holds for brown firms, which reduce production. From a quantitative point of view, the impact of green QE is small. Even in the scenario with infinite adjustment costs $(\eta=0$, black solid line in Figure 1$)$, emissions fall on impact by $0.6 \%$, and they come back to the steady state after some years, given that the shock is transitory. The fall in pollution is two orders of magnitude smaller, and much more persistent. The effects on aggregate variables is invisible: the TFP rise resulting from a lower pollution barely affects aggregate variables.

Why does Green QE have small effects on pollution? The economic intuition is the following. In our model, atmospheric carbon follows an extremely persistent law of motion: even large changes in the emission flows would have small effects on the pollution stock on impact. Given that Green QE is transitory, emissions come back to the steadystate after some quarters, implying that the medium-run effects on pollution are small too. In addition, the damage function yields a steady-state output loss of only $0.7 \%$, much lower than the inefficiencies arising from monopolistic competition and financial frictions. The low steady-state output loss also implies a low first derivative of damage with respect to pollution. These implications rely on the calibration that we borrow from Heutel (2012), who in turn builds on Nordhaus (2008). Their estimates imply that the 2018 value of atmospheric carbon (used to calibrate our model) yields a low output loss. Output loss becomes bigger if atmospheric carbon reaches a value such that the mean temperature increase with respect pre-industrial level is beyond $2^{\circ}$. The combination of a low effect of emissions on the pollution stock and a low effect of pollution on TFP explains the extremely small impact of Green QE on macroeconomic variables. ${ }^{18}$ It is worthy highlighting that, absent TFP damages, Green QE has no effect on aggregate variables, regardless of the assumption on the substitutability between bonds: the reduction in brown capital would be fully offset by an increase in green capital.

\subsection{QE Shock: Green vs market neutral}

We simulate the effects of a 10\% temporary increase in central bank's assets. We compare two scenarios. In the first scenario the central bank does not change the asset composition: QE is market neutral (blue solid line, Figure 2), because the intervention does not affect the spread between green and brown bonds. This policy puts downward pressure on the interest rate paid by green and brown firms, which both raise physical capital and production: emission and pollution slightly rise. Banks reduce investment

\footnotetext{
${ }^{18}$ In Section 5.3 we consider a faster process for pollution and higher steady-state damage.
} 
in green and brown firms, in response to lower lending rates. Total output rises, driving inflationary pressures: the policy rate increases and consumption is depressed on impact.

In the second scenario, the intervention is entirely targeted to green bonds (black dotted line, Figure 2): this is a Green QE that increases the size of the central bank's balance sheet. We replace the Green $\mathrm{QE}$ rule (equation 43 ) with $b_{P t}=b_{P}$ : brown bonds held by the central bank remain in the steady state. Unlike the simulation in Figure 1 where the size of central bank's assets is kept constant, the increase in green bond is not offset by a reduction in brown bond, but it is financed with higher liabilities. ${ }^{19}$ When brown and green bonds are imperfect substitutes $(\eta=10)$, the spread between green and brown bonds slightly decreases. Banks reduce green and buy brown bonds, but not enough to offset the central bank's intervention: brown firms can finance lower capital costs, and the rise in brown output and emissions are smaller. Although the intervention is targeted exclusively to the green sector, in the first quarters emissions and pollution increase, as a result of the economic expansion driven by unconventional monetary policy. There is still a trade-off between business cycle and environment, even if the central bank use highly "environmental friendly" monetary instruments. With regard to aggregate macroeconomic variables, the difference between the two scenarios is in fact invisible: this is the result of the tiny effects of Green QE, highlighted in Figure 1.

\subsection{A Green QE rule}

What is the role of Green QE in mitigating emissions during expansion periods? We simulate the effects of an exogenous $1 \%$ increase in TFP and compare two scenarios.

In the first scenario, the Green QE rule is off $\left(\phi_{G}=0\right.$ in equation 43$)$. The effect of the TFP shock is standard. Economic activity expands. Inflation falls as a result of higher supply. Banking profits rise and the increase in net worth is higher than the increase in lending: leverage ratio is lower, lending rates fall. The increase in TFP is common to green and brown sectors: emission and pollution grow.

In the second scenario, we activate the Green QE rule with $\phi_{G}=10$ : the rule prescribes an increase in the share of central banks' green assets by $10 \%$ if brown output rises by 1\%. Procyclical Green QE partially mitigates the brown output increase and the resulting emissions. The transmission mechanism is now well understood: banks face a reduction in the green-brown spread and change their portfolio toward brown bonds. This shift does not offset the central bank's intervention as a result of adjustment costs (we keep $\eta=10$ ). Brown firms reduce capital, despite the increase in TFP. The rise in capital is amplified for green firms.

\footnotetext{
${ }^{19}$ Central bank's liabilities are public bonds: we are assuming a cashless economy where the government and the central bank are a single entity.
} 


\section{Green QE Shock}
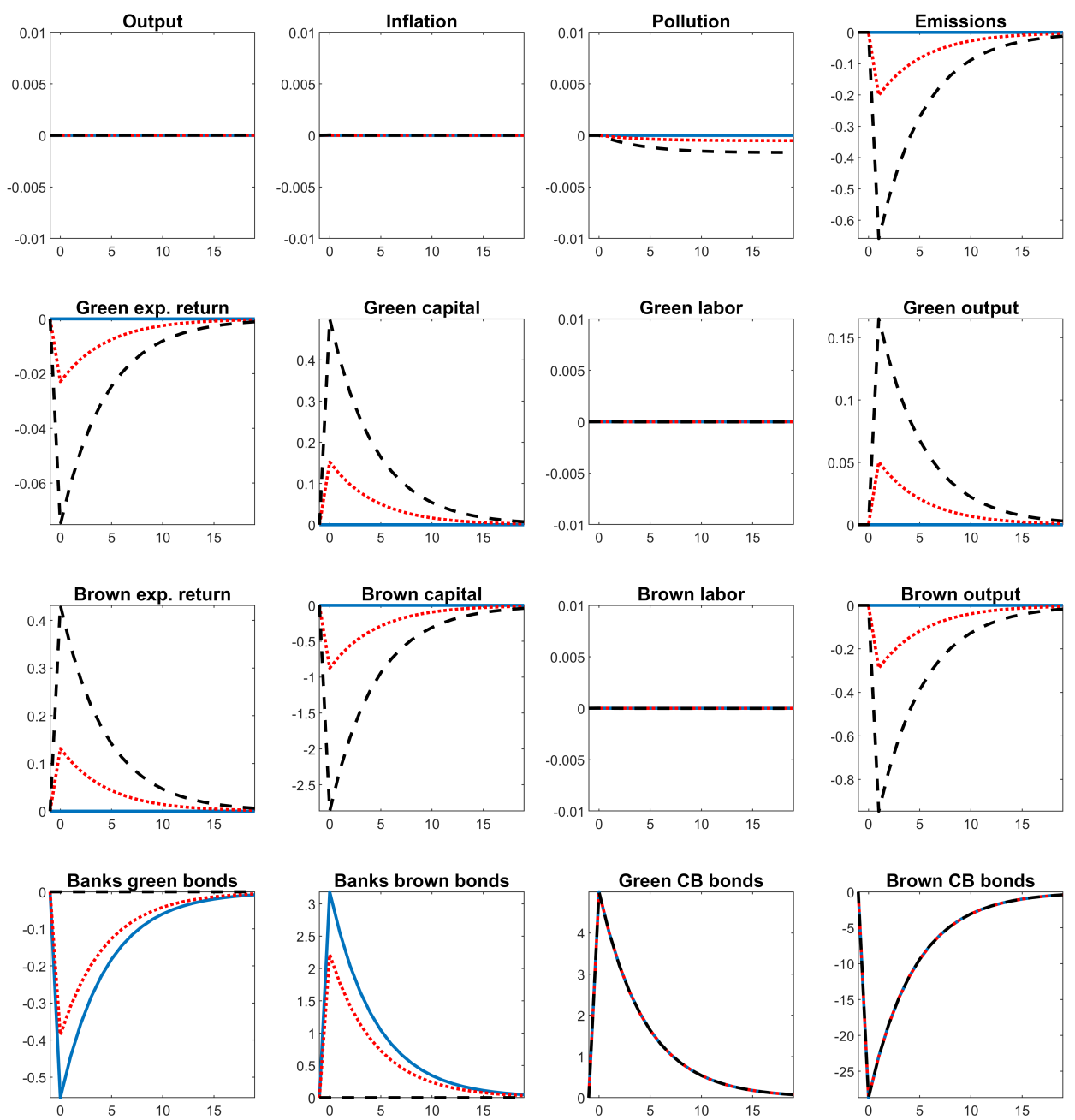

Figure 1: IRFs to a 5\% positive GQE shock. Responses are in log-deviations from the steady state, except for inflation and spreads, whose response is in quarterly percent deviations from the steady state reported at annual rates. Blue solid line: $\eta \rightarrow \infty$ (no adjustment cost). Red dotted line: $\eta=10$. Black dashed line: $\eta=0$ (infinite adjustment costs). 


\section{QE Targeted to Green Bonds}
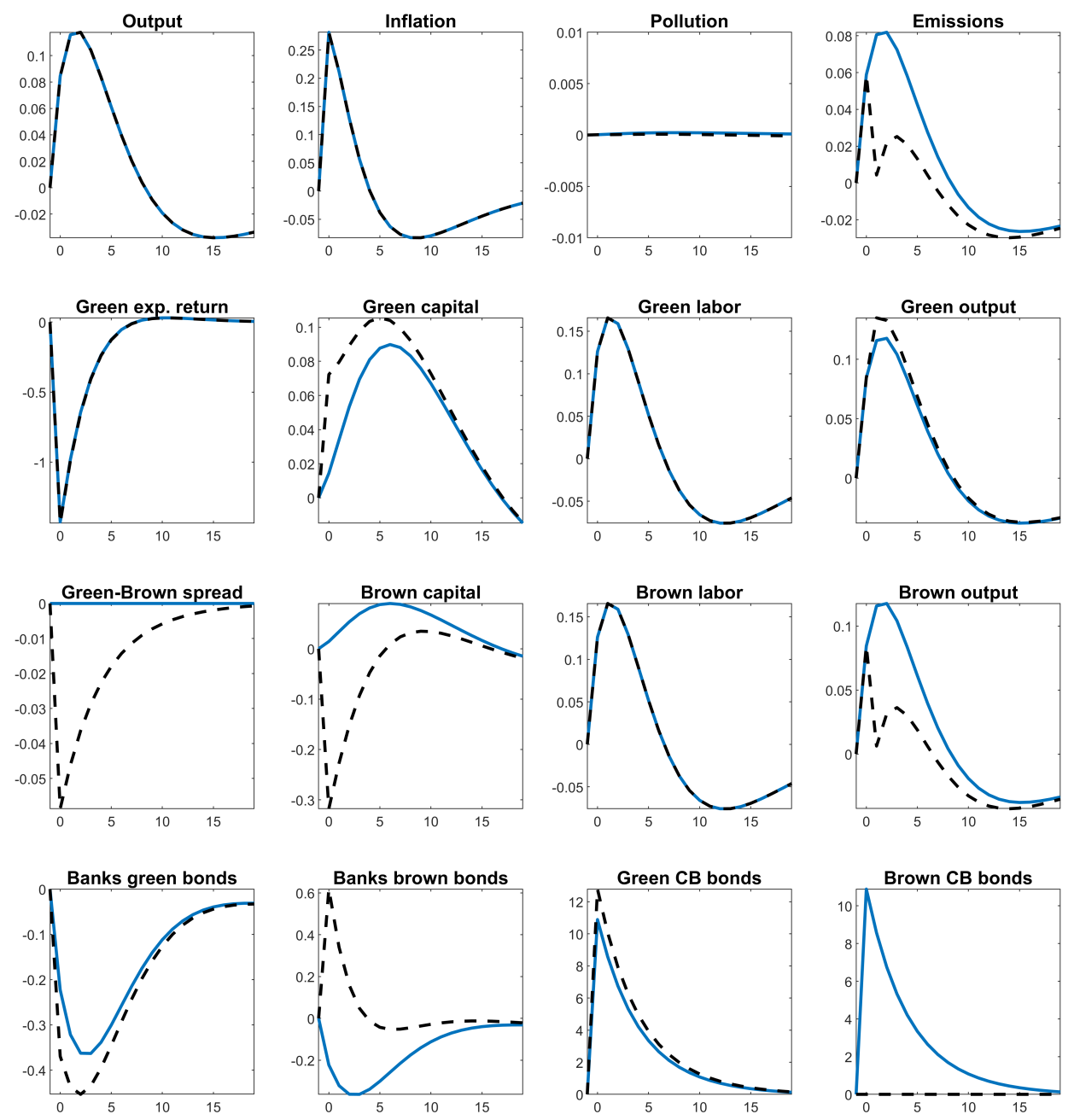

Figure 2: IRFs to a 10\% positive QE shock. Responses are in log-deviations from the steady state, except for inflation and spreads, whose response is in quarterly percent deviations from the steady state reported at annual rates. Blue solid line: the composition of green and brown bonds in central bank's balance sheet does not change. Black dashed line: QE is entirely targeted to green bonds. 


\section{TFP Shock and Endogenous GQE}
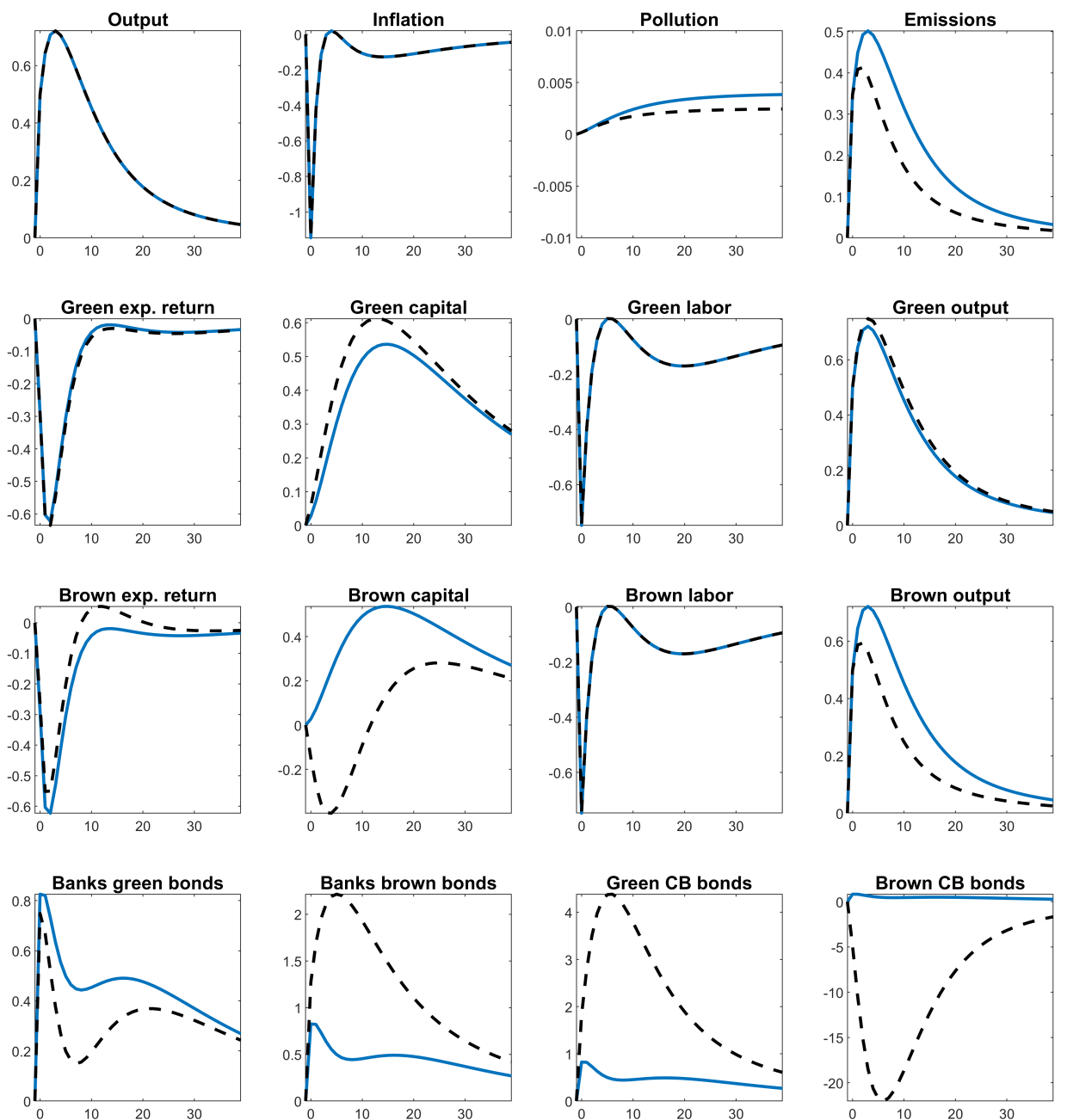

Figure 3: IRFs to a $1 \%$ positive TFP shock. Responses are in log-deviations from the steady state, except for inflation and spreads, whose response is in quarterly percent deviations from the steady state reported at annual rates. Blue solid line: Green QE does not respond. Black dashed line: Green QE responds to brown production with $\phi_{G}=10$. 


\section{Welfare Analysis}

\subsection{The efficient allocation}

Our model features both inefficiencies that affect the steady state (static) and inefficiencies that affect the dynamics of the model (dynamic). Static inefficiencies include: IA) monopolistic competition, which creates a wedge between the marginal product and the marginal cost of inputs used by intermediate-good firms. IB) The banking friction, which opens up a credit spread between the marginal product of capital and the stochastic discount rate. Dynamic inefficiencies include: IIA) price adjustment costs. IIB) A time-varying credit spread (see friction IB). IIC) Bank adjustment costs. Finally, the pollution externality affects both the steady state and the dynamics. Frictions IA and IIA are standard in New Keynesian models, to study the role of monetary policy. Frictions IB and IIB are common in models studying the effect of QE (or macroprudential policy). We introduce IIC and the pollution externality in order to analyze the effects of Green QE.

We characterize the problem of a social planner that is not subject to any of these frictions and internalizes the pollution externality. We label the social planner's allocation as the efficient allocation and we use the subscript $e$ to denote these variables. The social planner solves the following problem:

$$
\begin{gathered}
\max _{\left\{c_{e t}, i_{e t}, h_{e t}^{G}, h_{e t}^{B}, k_{e t}^{B}, k_{e t}^{G}, y_{e t}^{B}, y_{e t}^{G}, x_{e t}\right\}_{t=0}^{\infty}} \mathbb{E}_{0} \sum_{t=0}^{\infty} \beta^{t}\left(\frac{c_{e t}^{1-\sigma}}{1-\sigma}-\frac{\left(h_{e t}^{B}+h_{e t}^{G}\right)^{1+\varphi}}{1+\varphi}\right) \\
\text { s.t. }\left\{\begin{array}{lc}
c_{e t}+i_{e t}+g=\left[(1-\zeta)^{\frac{1}{\xi}}\left(y_{e t}^{G}\right)^{\frac{\xi-1}{\xi}}+\zeta^{\frac{1}{\xi}}\left(y_{e t}^{B}\right)^{\frac{\xi-1}{\xi}}\right]^{\frac{\xi}{\xi-1}} & \lambda_{t} \\
k_{e t}^{G}+k_{e t}^{B}=(1-\delta)\left(k_{e t-1}^{G}+k_{e t-1}^{B}\right)+\left[1-\frac{\kappa_{I}}{2}\left(\frac{i_{e t}}{i_{e t-1}}-1\right)^{2}\right] i_{e t} & \lambda_{e t} q_{e t} \\
y_{e t}^{G}=\left[1-\left(d_{0}+d_{1} x_{e t}+d_{2} x_{e t}^{2}\right)\right] a_{t}\left(k_{e t-1}^{G}\right)^{\alpha} h_{e t}^{G(1-\alpha)} & \lambda_{e t} p_{e t}^{G} \\
y_{e t}^{B}=\left[1-\left(d_{0}+d_{1} x_{e t}+d_{2} x_{e t}^{2}\right)\right] a_{t}\left(k_{e t-1}^{B}\right)^{\alpha} h_{e t}^{B(1-\alpha)} & \lambda_{e t} p_{e t}^{B} \\
x_{e t}=\left(1-\delta_{x}\right) x_{e t-1}+\left(y_{e t}^{B}\right)^{1-\psi}+e^{r o w} & -\lambda_{e t} p_{e t}^{x},
\end{array}\right.
\end{gathered}
$$

where on the right of each constraint we have placed the associated multiplier. The first constraint is the resource constraint: consumption (private and public) plus investment equals the production function of the final good. ${ }^{20}$ The second constraint is the law of

\footnotetext{
${ }^{20}$ We have already imposed that the social planner produces the same amount of each intermediate good. This implies that by equation (3) the amount of the final good $y_{t}$ is equal to the amount of every intermediate good $y_{t}^{I}(i)$. Given the concavity of the CES aggregator in equation (3), choosing the same amount of every intermediate good is indeed optimal.
} 
motion of capital. The third and the fourth constraint are the production function of green and brown firms. The last constraint is the law of motion of atmospheric carbon. The optimality conditions with respect to brown output implies: ${ }^{21}$

$$
p_{e t}^{B}=\zeta^{\frac{1}{\xi}}\left(\frac{y_{e t}^{B}}{y_{t}}\right)^{-\frac{1}{\xi}}-(1-\psi)\left(y_{e t}^{B}\right)^{-\psi} p_{e t}^{x}
$$

where $p_{t}^{X}$ is the social cost of pollution, given by the first-order condition on $x_{t}$ :

$$
p_{e t}^{x}=\frac{\left(d_{1}+2 d_{2} x_{t}\right)}{\left[1-\left(d_{0}+d_{1} x_{t}+d_{2} x_{e t}^{2}\right)\right]}\left(p_{e t}^{G} y_{e t}^{G}+p_{e t}^{B} y_{e t}^{B}\right)+\beta\left(1-\delta_{x}\right) \mathbb{E}_{t}\left[\left(\frac{c_{e t}}{c_{e t+1}}\right)^{\sigma} p_{e t+1}^{x}\right] \text {. }
$$

The competitive-equilibrium counterpart of equations (49) is the following:

$$
\frac{p_{t}^{B}}{p_{t}^{I}}=\zeta^{\frac{1}{\xi}}\left(\frac{y_{t}^{B}}{y_{t}}\right)^{-\frac{1}{\xi}}
$$

Equation (49) states that the shadow value of brown production $p_{e t}^{B}$ has to be equal to the marginal product of brown production minus the marginal cost of the pollution externality, captured by the social cost of pollution $p_{e t}^{x}$. Equation (50) is a Euler equation for pollution: the marginal cost of having an additional unit of pollution today is equal to the marginal damage on TFP plus the future discounted cost of an additional unit of pollution in the next period, net of depreciation.

In the competitive equilibrium (equation 51), the pollution externality is not internalized. In addition, monopolistic competition and price rigidities introduce a time-varying wedge $\left(p_{t}^{I}\right)$ between the marginal cost and the marginal product of brown output. In the competitive equilibrium, the $p_{t}^{I}$ wedge applies also to the green-output counterpart of equation (51).

\subsection{Permanent policy}

Before studying the welfare gains of Green QE, it is useful to compute the welfare gains of Pigovian constant taxes/subsidies. We assume that the social planner has three tax instruments available. The social planner can tax i) the capital costs of green and brown firm (instrument $\tau_{K}$ ); the cost of brown and green inputs for intermediate firms $\left(\tau_{Y}\right)$; the cost of brown input only for intermediate firms (instrument $\tau_{B}$ ). The first two tax instruments address the credit-spread and the the monopolistic-competition inefficiency, respectively. The third tax rate addresses the pollution externality.

First, we compute the constant tax rates that make the steady state of the competitive

\footnotetext{
${ }^{21}$ The full set of efficient conditions is in the Appendix.
} 
equilibrium equal to the steady state of the efficient allocation. Second we compute numerically the constant tax rates that maximize welfare outside the steady state.

\subsubsection{Deterministic Steady State}

The following tax rates make the deterministic steady state of the competitive equilibrium equal to the steady state of the efficient allocation.

$$
\begin{aligned}
\tau_{Y}^{*} & =-\frac{1}{\varepsilon}=-16.7 \% \\
\tau_{K}^{*} & =\frac{\frac{1}{\beta}-(1-\delta)}{s p+\frac{1}{\beta}-(1-\delta)}-1=-6.7 \% \\
\tau_{B}^{*} & =\frac{1}{1-(1-\psi)\left(y_{e}^{B}\right)^{-\psi} p_{e}^{x}\left(\frac{y_{e}^{B}}{\zeta y_{e}}\right)^{\frac{1}{\xi}}}-1=0.4 \% .
\end{aligned}
$$

Optimal $\tau_{Y}$ is standard in New Keynesian models that assume an efficient steady-state. The tax is negative, meaning that intermediate firms are subsidized to increase production. If $\varepsilon \rightarrow \infty$, differentiated goods are perfect substitutes, which implies that firms operate in perfect competition and optimal tax is 0 .

Optimal $\tau_{K}$ is also negative, meaning that green and brown firms are subsidized in order to undo the credit-spread friction. If steady-state spread $s p$ is 0 , optimal $\tau^{K}$ is also 0 .

Optimal $\tau_{B}$ internalizes the externality of brown output. The tax increases in the marginal damage of brown output $(1-\psi)\left(y^{B}\right)^{-\psi}$; it increases in the marginal cost of pollution $p_{e}^{x}$; it decreases in the marginal product of brown output $\left(\frac{y_{e}^{B}}{\zeta y_{e}}\right)^{-\frac{1}{\xi}}:$ if by increasing brown output, intermediate firms can substantially expand intermediate output, the social planner is less willing to tax. The tax is small in absolute value, compared to the other two subsidies. This is the result of the relatively low output loss in Nordhaus (2008), using current values of atmospheric carbon: in a steady-state without taxes, pollution generates a damage equal to $0.7 \%$ of output in our model. The output loss of monopolistic competition and leverage constraints are much bigger. This result changes if we calibrated the model using a higher steady state value for atmospheric carbon $x$.

\subsubsection{Dynamics}

What is the optimal constant tax on brown production, in an economy hit by TFP shocks? To address this question, we take a second order approximation of the model around the deterministic steady state, under TFP shocks only. We assume a standard 
deviation of TFP shocks equal to $1 \%$. We set $\tau_{K}=\tau_{K}^{*}$ and $\tau_{Y}=\tau_{Y}^{*}$. We numerically search for the $\tau_{B}$ that maximizes expected welfare, conditional on being in the stochastic steady before the implementation of the tax. ${ }^{22}$ By maximizing expected conditional welfare, we are taking into account the transitional dynamics from the starting point (i.e. the stochastic steady state) to the equilibrium under the new policy. Conditional welfare is defined as follows:

$$
\mathcal{W}_{0}=\left(\frac{c_{0}^{1-\sigma}}{1-\sigma}-\frac{h_{0}^{1+\varphi}}{1+\varphi}\right)+\beta \mathbb{E}_{0}\left(\mathcal{W}_{1}\right)
$$

where in period 0 the economy is in the stochastic steady state. The resulting optimal $\tau_{B}$ is $0.4 \%$, equal to the value that makes the steady state of the competitive equilibrium equal to the steady-state efficient allocation. This tax yields a welfare gain of $0.0002 \%$ in terms of steady-state consumption equivalent: this low value reflects the small output cost of pollution in our model. If we start from a steady state with a high value of atmospheric carbon the optimal tax rate and welfare gains would be much higher.

One possible experiment could be comparing the welfare gain of the brown tax with the welfare gain of Green QE. The tax considered in this section is constant: a fair comparison would be between the optimal constant brown tax and the optimal constant share of green bonds held by the central bank $\left(\mu^{G}\right)$. However, in this model Green QE does not have any effect in the long run, given that in the long run bank adjustment costs are 0 : it is easy to verify that the steady state of aggregate variables like output and consumption is not affected by $\mu^{G} \cdot{ }^{23}$

\subsection{Cyclical policy}

How much should the central bank buy green and sell brown bonds, when brown production increases? In this section, we address this question through the following thought experiment. We take an approximation of the model around the deterministic steady state and we consider the same welfare function in equation (55). We numerically search for the Green QE parameter $\phi^{G}$ that maximizes the welfare impact response to a one-standard-deviation positive TFP shock. This exercise is different from the common practice of optimizing simple rules by maximizing welfare conditional on future shocks, both positive and negative. We choose this approach because we see Green QE as a policy tool available during expansion periods only. Otherwise, the central bank should buy brown and sell green bonds during recessions: such a policy would be politically

\footnotetext{
${ }^{22}$ The stochastic steady state is defined as the equilibrium after a long period without shocks, but assuming that agents know that in the future TFP shocks could still happen. Instead, in the deterministic steady state there is no uncertainty and all current and future shocks are set to 0 .

${ }^{23}$ Notice that also in Gertler and Karadi (2011) and Chen et al. (2012), the steady state of the model is independent from the size of central bank balance sheet.
} 
hard to support and ethically questionable. This approach is similar in spirit to Gertler and Karadi (2011)'s welfare analysis: in computing the optimal QE policy, the authors only consider a crisis episode. Similarly, we consider an expansion period in which brown production increases. We find that during a TFP-driven expansion, the central bank should aggressively respond to the brown output rise by selling brown bonds and buying green bonds. The optimal $\phi^{G}$ is the upper bound of the grid even when the upper bound is higher than 100. Such high values are of little use for policy makers: a value of 100 implies that a $0.2 \%$ increase in brown production would induce the central bank to increase the green bond share $\mu_{t}^{G}$ by $20 \%$, and thus to hold only green bonds, according to our baseline calibration. As in Gertler and Karadi (2011), given that we are simulating a single event, we define the consumption equivalent as the percentage gain in consumption in the first four quarters that would make welfare under no Green QE equal to welfare under optimal Green QE. With $\phi_{G}=100$, this measure of consumption equivalent is small, around to $0.002 \%$ of steady-state consumption. ${ }^{24}$ The low welfare gain is the result of two features of the model: the low output loss of pollution; the extremely persistent law of motion of atmospheric carbon, whereby a temporary policy such as Green QE is not appropriate. Unlike Gertler and Karadi (2011), we are not imposing any inefficiency cost from central bank's intermediation. The presence of these costs would further undermine the case for Green QE.

\section{Sensitivity Analysis}

\section{$5.1 \quad$ Utility externality}

In our model, Green QE is potentially effective in the short term and it is neutral in the long term. So far, the pollutant considered in this model is carbon dioxide, a stock pollutant which remains in the atmosphere for several decades. In this paragraph we consider pollutants such as sulfur dioxide or nitrogen oxides, which are flow pollutants at the quarterly frequency. We assume that these pollutants are detrimental for the health of households, introducing the following cost in the utility function:

$$
\operatorname{Cost}_{t}=-\frac{\omega_{1}}{1+\omega_{2}} y_{t}^{B\left(1+\omega_{2}\right)}
$$

\footnotetext{
${ }^{24}$ In this welfare exercise, we are approximating the model at the first order. At the second order, we would need to use the so called "pruning", to keep the model stationary, as it is normally done by the literature. However, given the tiny welfare gains that we find, this procedure would make our welfare results unreliable. Given that we are carrying out a welfare analysis under a single expansions and not under a long series of positive and negative shocks, we believe that a first-order approximation is enough for our purpose.
} 
which is increasing in brown production. The utility cost is not internalized by households, so the impulse response functions of macroeconomic and environmental variables do not change. Results of the welfare analysis quantitatively changes. Calibrating the parameters of the cost function is not obvious and we experiment different values (Table 2 ). For each combination of parameters we report the following results: the steady-state consumption cost of brown production (third row); the tax on brown output that would equalize the steady-state of the competitive equilibrium with the steady state of the social planner, as in Section 4.2.1 (fourth column); the optimal tax outside the steady state and the associated consumption gain, as done in Section 4.2 .2 (fifth column); the welfare gain of Green QE during an expansion, measured as in Section 4.3 (sixth column). We keep the baseline TFP damage of atmospheric carbon and we set the adjustment costs to $\eta=10$. The first row of Table 2 reports the baseline calibration with no utility cost: taxes are still positive as a result of the TFP cost of pollution. The welfare gain of Green QE during an expansion becomes substantial when the utility cost of pollution is around $5 \%$ : for the same utility cost (fifth vs sixth row), the welfare gain of Green QE is higher if the cost function is more convex. This analysis shows that cyclical Green QE may feature relevant welfare gains, if pollution is modeled as a flow variable.

\begin{tabular}{|c|c|c|c|c|c|}
\hline$\omega_{1}$ & $\omega_{2}$ & Cost & Tax (SS) & Tax (Dyn) \& Gain & Green QE Gain \\
\hline \hline 0 & 0 & 0 & $0.4 \%$ & $0.4 \%$, Gain: $0.0002 \%$ & $0.002 \%$ \\
\hline 0.01 & 0 & $0.51 \%$ & $1.8 \%$ & $1.8 \%$, Gain: $0.004 \%$ & $0.011 \%$ \\
\hline 0.01 & 1 & $0.13 \%$ & $1.1 \%$ & $1.1 \%$, Gain: $0.002 \%$ & $0.007 \%$ \\
\hline 0.1 & 0 & $5.41 \%$ & $15.3 \%$ & $15.1 \%$, Gain: $0.244 \%$ & $0.085 \%$ \\
\hline 0.39 & 1 & $5.41 \%$ & $26.4 \%$ & $26.2 \%$, Gain: $0.786 \%$ & $0.168 \%$ \\
\hline
\end{tabular}

Table 2: Pollution in the utility function.

\subsection{Brown-sector size}

In the baseline calibration, we set parameter $\zeta$ in order to match a given steady state of pollution. The resulting value is 0.1485 , which implies a low share for the brown sector. In this paragraph we set $\zeta=0.9$. We introduce a new parameter $\kappa_{B}$ in the emission function as follows:

$$
e_{t}=\kappa_{B}\left(y_{t}^{B}\right)^{1-\psi}
$$

We set $\kappa_{B}$ to 0.2854 , in order to have a steady-state pollution of 867 gigatons of carbon, as in the baseline calibration. We consider three scenarios. ${ }^{25}$ The first scenario is the baseline calibration, where $\zeta$ is low (Figure 4, blue solid line). In the second scenario,

\footnotetext{
${ }^{25}$ In all scenario, we set infinite adjustment costs.
} 
we set $\zeta$ to 0.9 (Figure 4, black dashed line). Under this calibration, the central bank holds only $10 \%$ of green bonds in its portfolio. When the allocation between green bonds and brown bonds is $10-90 \%$, a percentage share increase by $5 \%$ in green bonds implies that allocation becomes $10.5-89.5 \%$ : this is a small shock and the reduction of brown output is negligible. This induces us to increase the size of the shock by 10 times in the third scenario (Figure 4, red dotted line). Green production rises, given the size of the shock. Brown production falls by less compared to the baseline calibration, given the smaller reduction in brown bonds, even under a Green QE shock of 50\%. By further increasing the shock, we could obtain a larger fall in brown output. However, parameter $\zeta$ does not seem relevant in driving our results.

\subsection{Damage and pollution persistence}

In the impulse-response analysis we argue that the low effects of Green QE rely on the low steady-state damage and on the high persistence of the pollution process. In this paragraph we increase the steady-state damage and we reduce the decay rate of pollution. We plot a Green QE shock under three scenarios. In the first scenario, we use the baseline calibration (Figure 5, blue solid line). In the second scenario (Figure 5, red dotted line), we set the decay rate of pollution to 0.5 : this value is arbitrarily low to show how results change with a fast law of motion of pollution. ${ }^{26}$ A fast law of motion increases the impact derivative of pollution with respect to emissions: pollution falls by $0.1 \%$ on impact. However, the low derivative of damage with respect to pollution results in a negligible output effects. In the third scenario (Figure 5, black dashed line), we keep $\delta_{x}=0.5$ and we modify the damage function (equation 34) as follows:

$$
D_{t}=d_{3}\left(d_{0}+d_{1} x_{t}+d_{2} x_{t}^{2}\right)
$$

We set $d_{3}=7.5$, implying a big steady-state damage (about $5 \%$ of TFP) and a higher derivative of TFP damage with respect to pollution. The output gain is larger compared to the previous scenarios, but still quite low: on impact output rises by about $0.012 \%{ }^{27}$

In this paragraph we have shown that the decay rate of pollution and the steady-state damage are two important factors in shaping the impulse response function to a Green QE shock. Nevertheless, even when we force these parameters to extreme values, output

\footnotetext{
${ }^{26} \mathrm{~A}$ decay rate of 0.5 implies a half-life of atmospheric carbon of one quarter. In the baseline calibration, the decay rate implies a half-life of atmospheric carbon of 83 years, as in Heutel (2012). Moore III and Braswell (1994) estimate the half-life of atmospheric carbon dioxide between 19 and 92 years.

${ }^{27}$ In all scenarios we set infinite adjustment costs, we keep $\zeta=0.1485$ and we adjust $\kappa_{B}$ accordingly. In the first scenario $\kappa_{B}=1$, as in the baseline calibration. In the second scenario $\kappa_{B}=238$. In the third scenario $\kappa_{B}=246$.
} 
gains are still very low.

Green QE shock: different brown sector sizes
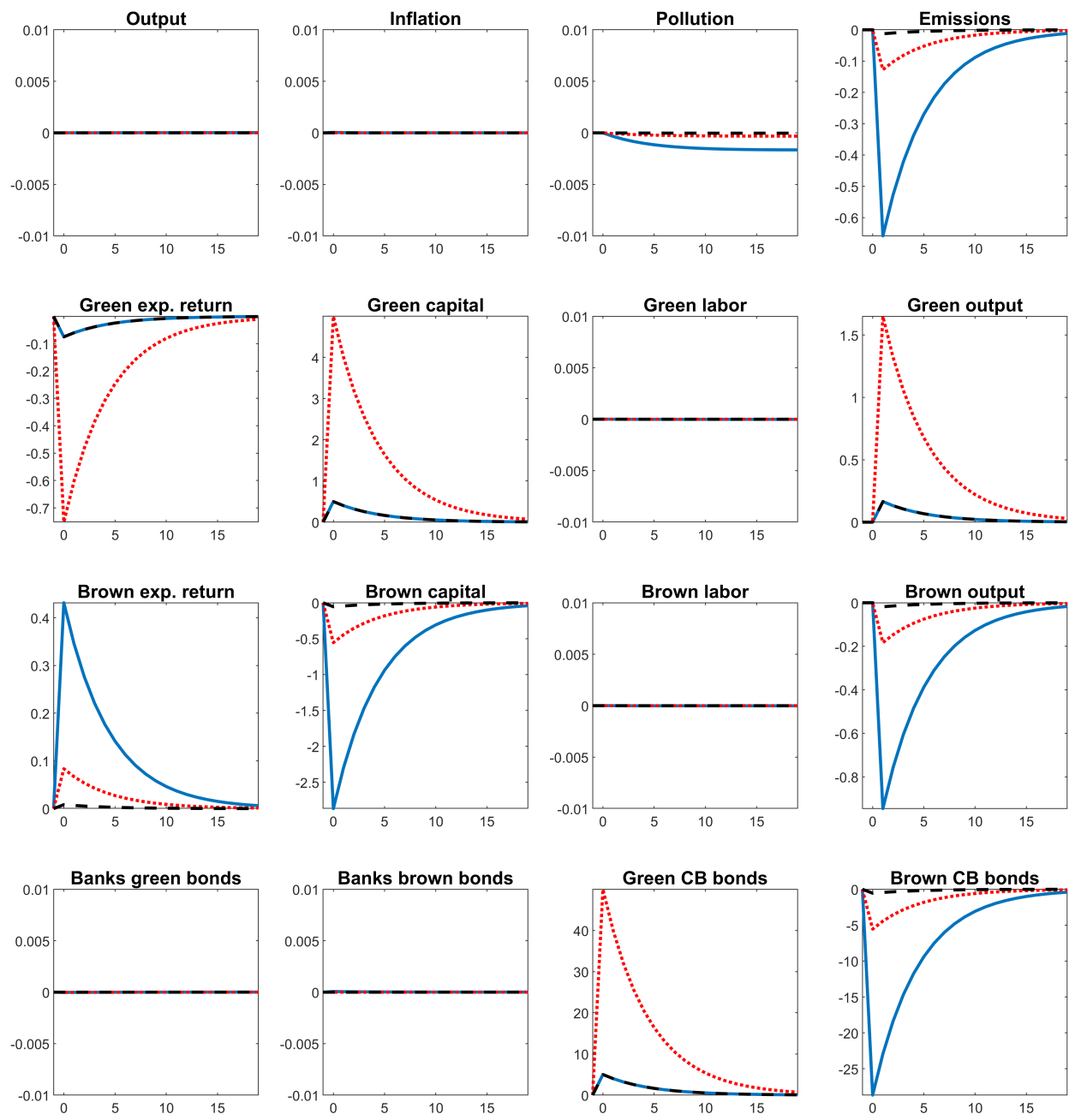

Figure 4: IRFs to a positive GQE shock. Responses are in log-deviations from the steady state, except for inflation and spreads, whose response is in quarterly percent deviations from the steady state reported at annual rates. Blue solid line: $\zeta=0.1485$, the shock is $5 \%$. Red dotted line: $\zeta=0.9$, the shock is $50 \%$. Black dashed line: $\zeta=0.9$, the shock is $5 \%$. 


\section{Green QE Shock: different persistence and damage of pollution}
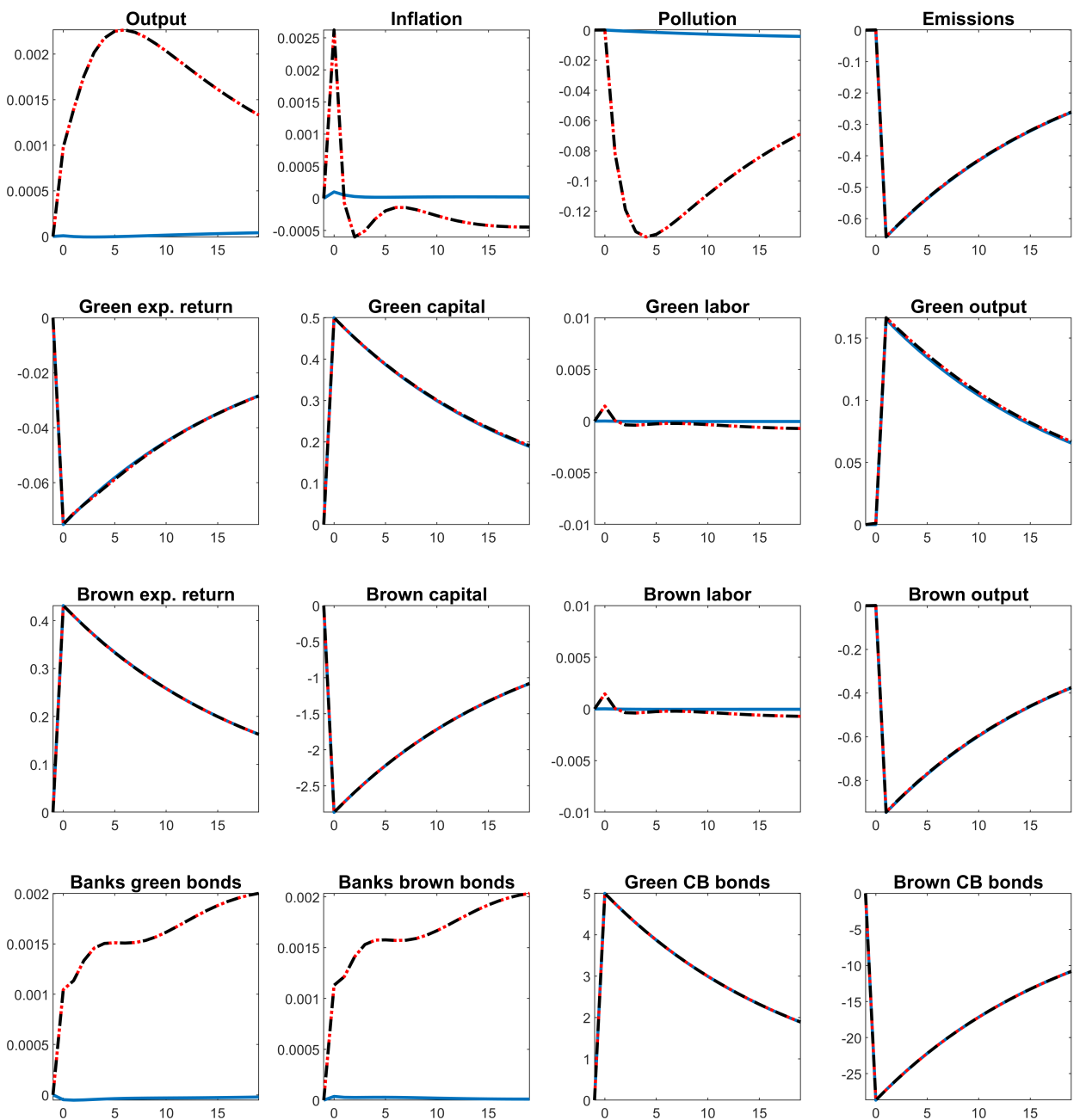

Figure 5: IRFs to a 50\% positive GQE shock. Responses are in log-deviations from the steady state, except for inflation and spreads, whose response is in quarterly percent deviations from the steady state reported at annual rates. Blue solid line: $d_{3}=1$ and $\delta_{x}=0.9979$. Red dotted line: $d_{3}=1$ and $\delta_{x}=0.5$. Black dashed line: $d_{3}=7.5$ and $\delta_{x}=0.5$. 


\section{Concluding Remarks}

We have set up a model to study the effects of a temporary Green QE on macroeconomic and environmental variables. We show that a necessary condition for Green QE to be effective is that green and brown bonds are imperfect substitutes. Under the hypothesis of imperfect substitutability, our results point out that Green QE is able to reduce the flow of detrimental emissions, even if the effect is not large. Given that we model a temporary Green QE, emissions come back to the steady state after some quarters, only slightly affecting the stock of pollution, which is extremely persistent. We also find that if the flow of emissions enter directly the utility function or pollution follows a faster law of motion, Green QE is more effective.

We believe that climate change is a serious challenge that should be carefully addressed by policy makers around the world. Our results do not imply that climate change is a minor concern. Our findings do imply that a temporary Green QE is an imperfect instrument in affecting slow-moving variables such as atmospheric carbon.

This is a first tentative to model Green QE in a standard macroeconomic framework. We invite the reader to cautiously interpret our results, with some caveats that should be kept well in mind. As in other DSGE models, in our setup monetary policy does not have permanent effects on the real economy, and we cannot study the effects of a permanent Green QE. However, it is possible that the central bank may still be able to affect the long-run behavior of economic agents, through other incentives or moral suasion. Moreover, we do not take into account that a temporary Green QE may still be useful along a transition between a steady state with high emissions and a steady state with low emissions. Our framework could be extended to study scenarios where Green QE may have long-run effects. If abatement technologies that permanently reduce emissions are available, one could compare different policies to finance these investments: is it better financing green investment with taxes, with debt or with central bank's instruments? We leave these issues for future research. 


\section{Bibliography}

Angelopoulos, K., G. Economides, And A. Philippopoulos (2013): "First-and Second-Best Allocations under Economic and Environmental Uncertainty," International Tax and Public Finance, 20, 360-380.

Annicchiarico, B. And F. Di Dio (2015): "Environmental Policy and Macroeconomic Dynamics in a New Keynesian Model," Journal of Environmental Economics and Management, 69, 1-21.

Barrage, L. (2020): "Optimal Dynamic Carbon Taxes in a Climate-Economy Model with Distortionary Fiscal Policy," The Review of Economic Studies, 87, 1-39.

Bartocci, A. And M. Pisani (2013): "Green Fuel Tax on Private Transportation Services and Subsidies to Electric Energy. A Model-Based Assessment for the Main European Countries," Energy economics, 40, S32-S57.

Benigno, P. (2009): "Price Stability with Imperfect Financial Integration," Journal of Money, Credit and Banking, 41, 121-149.

Burlon, L., A. Gerali, A. Notarpietro, And M. Pisani (2018): "Non-Standard Monetary Policy, Asset Prices and Macroprudential Policy in a Monetary Union," Journal of International Money and Finance, 88, 25-53.

CARney, M. (2015): "Breaking the Tragedy of the Horizon: Climate Change and Financial Stability," Speech at Llyod's of London, https://www.socialeurope.eu/greenmoney-without-inflation.

Chan, Y. T. (2020): "Are Macroeconomic Policies Better in Curbing Air Pollution than Environmental Policies? A DSGE Approach with Carbon-Dependent Fiscal and Monetary Policies," Energy Policy, 141, 111454.

Chen, H., V. Cúrdia, And A. Ferrero (2012): "The Macroeconomic Effects of Large-Scale Asset Purchase Programmes," The Economic Journal, 122, F289-F315.

Christiano, L. J., M. Eichenbaum, And C. L. Evans (2005): "Nominal Rigidities and the Dynamic Effects of a Shock to Monetary Policy," Journal of Political Economy, $113,1-45$.

Curdia, V. And M. Woodford (2011): "The Central-Bank Balance Sheet as an Instrument of Monetary Policy," Journal of Monetary Economics, 58, 54-79. 
Dafermos, Y., M. Nikolaidi, and G. Galanis (2018): "Climate Change, Financial Stability and Monetary Policy," Ecological Economics, 152, 219-234.

Diluiso, F., B. Annicchiarico, M. Kalkuhl, And J. C. Minx (2020): "Climate Actions and Stranded Assets: The Role of Financial Regulation and Monetary Policy," CEIS Working Paper, N. 501.

Fischer, C. And M. Springborn (2011): "Emissions Targets and the Real Business Cycle: Intensity Targets versus Caps or Taxes," Journal of Environmental Economics and Management, 62, 352-366.

Gertler, M. And P. Karadi (2011): "A Model of Unconventional Monetary Policy," Journal of Monetary Economics, 58, 17-34.

(2013): "Qe 1 vs. 2 vs. 3...: A Framework for Analyzing Large-Scale Asset Purchases as a Monetary Policy Tool," International Journal of Central Banking, 9, 5-53.

Giovanardi, F., M. Kaldorf, L. Radke, And F. Wicknig (2020): "Directing Investment to Green Finance: How Much Can Central Banks Do?" Mimeo.

Golosov, M., J. Hassler, P. Krusell, and A. Tsyvinski (2014): "Optimal Taxes on Fossil Fuel in General Equilibrium," Econometrica, 82, 41-88.

Heutel, G. (2012): "How should Environmental Policy Respond to Business Cycles? Optimal Policy under Persistent Productivity Shocks," Review of Economic Dynamics, $15,244-264$.

Moore III, B. And B. Braswell (1994): "The Lifetime of Excess Atmospheric Carbon Dioxide," Global Biogeochemical Cycles, 8, 23-38.

Nordhaus, W. D. (2008): A Question of Balance: Economic Modeling of Global Warming, Yale University Press. New Haven.

Ripple, W. J., C. Wolf, T. M. Newsome, P. Barnard, and W. R. Moomaw (2020): "World Scientists Warning of a Climate Emergency," BioScience, 70, 8-12.

Ripple, W. J., C. Wolf, T. M. Newsome, M. Galetti, M. Alamgir, E. Crist, M. I. Mahmoud, And W. F. Laurance (2017): "World Scientists Warning to Humanity: A Second Notice," BioScience, 67, 1026-1028.

Rogoff, K. (2019): "The Case for a Carbon Tax," Project Syndicate, https://www.project-syndicate.org/commentary/world-carbon-bank-for-developingcountries-by-kenneth-rogoff-2019-07?barrier=accesspaylog. 
Wallace, N. (1981): "A Modigliani-Miller Theorem for Open-Market Operations," American Economic Review, 71, 267-274. 


\section{Appendix}

\section{A Model Equations}

There are 45 equations for 45 endogenous variables:

$$
\begin{aligned}
X_{t} \equiv & {\left[\lambda_{t}, c_{t}, r_{k t}^{G}, r_{k t}^{B}, w_{t}, h_{t}, h_{t}^{B}, h_{t}^{G} y_{t}, k_{t}, k_{t}^{B}, k_{t}^{G}, q_{t}, i_{t}, r_{t}, p_{t}^{I}, \pi_{t}, y_{t}^{B}, y_{t}^{G}, p_{t}^{G}, p_{t}^{B}, n_{t}, \nu_{t}, l_{t}\right.} \\
& \left.l_{t}^{G}, s p_{t}^{B}, s p_{t}^{G}, s p_{t}^{G B}, r_{t}^{B}, r_{t}^{G}, b_{t}, b_{t}^{G}, b_{t}^{B}, b_{F t}, b_{P t}, b_{F t}^{G}, b_{F t}^{B}, b_{P t}^{G}, b_{P t}^{B}, \mu_{t}, \mu_{t}^{G}, A_{t}, x_{t}, e_{t}, a_{t}\right] .
\end{aligned}
$$

The model features 3 exogenous shocks:

$$
v_{t} \equiv\left[v_{t}^{a}, v_{t}^{q e}, v_{t}^{g q e}\right]
$$

The 45 equations are the following. Marginal utility of consumption:

$$
\lambda_{t}=c_{t}^{-\sigma}
$$

Euler equation:

$$
1=\beta \mathbb{E}_{t}\left(\frac{\lambda_{t+1}}{\lambda_{t}} \frac{r_{t}}{\pi_{t+1}}\right)
$$

Labor supply:

$$
h_{t}=\lambda_{t} w_{t}
$$

Law of motion of capital:

$$
k_{t}=(1-\delta) k_{t-1}+\left[1-\frac{\kappa_{I}}{2}\left(\frac{i_{t}}{i_{t-1}}-1\right)^{2}\right] i_{t} .
$$

Tobin Q:

$$
\begin{aligned}
1= & q_{t}\left\{1-\frac{\kappa_{I}}{2}\left(\frac{i_{t}}{i_{t-1}}-1\right)^{2}-\kappa_{I} \frac{i_{t}}{i_{t-1}}\left(\frac{i_{t}}{i_{t-1}}-1\right)\right\}+ \\
& +\beta \mathbb{E}_{t}\left[\frac{\lambda_{t+1}}{\lambda_{t}} q_{t+1}\left(\frac{i_{t+1}}{i_{t}}\right)^{2} \kappa_{I}\left(\frac{i_{t+1}}{i_{t}}-1\right)\right]
\end{aligned}
$$


Demand of green and brown output by intermediate firms:

$$
\begin{aligned}
y_{t}^{G} & =(1-\zeta)\left(\frac{p_{t}^{G}}{p_{t}^{I}}\right)^{-\xi} y_{t} \\
y_{t}^{B} & =\zeta\left(\frac{p_{t}^{B}}{p_{t}^{I}}\right)^{-\xi} y_{t} .
\end{aligned}
$$

Production function of intermediate firms:

$$
y_{t}=\left[(1-\zeta)^{\frac{1}{\xi}}\left(y_{t}^{G}\right)^{\frac{\xi-1}{\xi}}+\zeta^{\frac{1}{\xi}}\left(y_{t}^{B}\right)^{\frac{\xi-1}{\xi}}\right]^{\frac{\xi}{\xi-1}} .
$$

If $\xi=1$, the production function takes the following form:

$$
y_{t}=\left(y_{t}^{G}\right)^{1-\zeta}\left(y_{t}^{B}\right)^{\zeta}
$$

Phillips curve:

$$
\pi_{t}\left(\pi_{t}-\bar{\pi}\right)=\beta \mathbb{E}_{t}\left[\frac{\lambda_{t+1}}{\lambda_{t}} \pi_{t+1}\left(\pi_{t+1}-\bar{\pi}\right) \frac{y_{t+1}}{y_{t}}\right]+\frac{\varepsilon}{\kappa_{P}}\left(p_{t}^{I}-\frac{\varepsilon-1}{\varepsilon}\right) .
$$

Production function of green and brown output

$$
\begin{aligned}
y_{t}^{G} & =A_{t}\left(k_{t-1}^{G}\right)^{\alpha} h_{t}^{G(1-\alpha)} \\
y_{t}^{B} & =A_{t}\left(k_{t-1}^{B}\right)^{\alpha} h_{t}^{B(1-\alpha)} .
\end{aligned}
$$

Labor demand:

$$
\begin{aligned}
& (1-\alpha) p_{t}^{G} y_{t}^{G}=w_{t} h_{t}^{G} \\
& (1-\alpha) p_{t}^{B} y_{t}^{B}=w_{t} h_{t}^{B} .
\end{aligned}
$$

Capital demand:

$$
\begin{aligned}
\alpha p_{t}^{G} y_{t}^{G} & =r_{k t}^{G} k_{t-1}^{G} \\
\alpha p_{t}^{B} y_{t}^{B} & =r_{k t}^{B} k_{t-1}^{B}
\end{aligned}
$$


Rental rate of capital:

$$
\begin{aligned}
& r_{k t}^{G}=\left[r_{t}^{G} q_{t-1}-(1-\delta) q_{t}\right] \\
& r_{k t}^{B}=\left[r_{t}^{B} q_{t-1}-(1-\delta) q_{t}\right]
\end{aligned}
$$

Optimal leverage:

$$
l_{t}=\frac{\mathbb{E}_{t}\left\{\beta \frac{\lambda_{t+1}}{\lambda_{t}} \nu_{t+1}\left[\left(r_{t+1}^{G}-r_{t+1}^{B}\right) l_{t}^{G}+\frac{r_{t}}{\pi_{t+1}}-\frac{\kappa_{F G}}{2}\left(\frac{l_{t}^{G}}{l_{t}}-b^{*}\right)^{2}\right]\right\}}{\theta-\mathbb{E}_{t}\left\{\beta \frac{\lambda_{t+1}}{\lambda_{t}} \nu_{t+1}\left(r_{t+1}^{B}-\frac{r_{t}}{\pi_{t+1}}\right)\right\}} .
$$

Definition of leverage:

$$
l_{t}=\frac{b_{F t}}{n_{t}} .
$$

Bank's assets:

$$
b_{F t}=b_{F t}^{G}+b_{F t}^{B} .
$$

Evolution of net worth:

$$
n_{t}=\chi\left[\left(r_{t}^{G}-r_{t}^{B}\right) l_{t-1}^{G}+\left(r_{t}^{B}-\frac{r_{t-1}}{\pi_{t}}\right) l_{t-1}+\frac{r_{t-1}}{\pi_{t}}-\frac{\kappa_{F G}}{2}\left(\frac{l_{t-1}^{G}}{l_{t-1}}-b^{*}\right)^{2}\right] n_{t-1}+\iota b_{F t} .
$$

Bank's discount factor:

$$
\begin{aligned}
\nu_{t}= & (1-\chi)+ \\
& +\chi \beta \mathbb{E}_{t}\left\{\frac{\lambda_{t+1}}{\lambda_{t}} \nu_{t+1}\left[\left(r_{t+1}^{G}-r_{t+1}^{B}\right) l_{t}^{G}+\left(r_{t+1}^{B}-\frac{r_{t}}{\pi_{t+1}}\right) l_{t}+\frac{r_{t}}{\pi_{t+1}}-\frac{\kappa_{F G}}{2}\left(\frac{l_{t}^{G}}{l_{t}}-b^{*}\right)^{2}\right]\right\} .
\end{aligned}
$$

Arbitrage condition:

$$
\frac{\kappa_{F G}}{l_{t}}\left(\frac{l_{t}^{G}}{l_{t}}-b^{*}\right)=\frac{\mathbb{E}_{t}\left\{\beta \frac{\lambda_{t+1}}{\lambda_{t}} \nu_{t+1}\left(r_{t+1}^{G}-r_{t+1}^{B}\right)\right\}}{\mathbb{E}_{t}\left\{\beta \frac{\lambda_{t+1}}{\lambda_{t}} \nu_{t+1}\right\}}
$$


Spread definitions:

$$
\begin{aligned}
s p_{t}^{G} & =\mathbb{E}_{t}\left[r_{t+1}^{G}-\frac{r_{t}}{\pi_{t+1}}\right] \\
s p_{t}^{B} & =\mathbb{E}_{t}\left[r_{t+1}^{B}-\frac{r_{t}}{\pi_{t+1}}\right] \\
s p_{t}^{G B} & =\mathbb{E}_{t}\left[r_{t+1}^{G}-r_{t+1}^{B}\right]
\end{aligned}
$$

Definition of green leverage:

$$
l_{t}^{G}=\frac{b_{F t}^{G}}{n_{t}} .
$$

Market clearing for labor and capital:

$$
\begin{aligned}
h_{t} & =h_{t}^{G}+h_{t}^{B} \\
k_{t} & =k_{t}^{G}+k_{t}^{B} .
\end{aligned}
$$

Goods market clearing:

$$
y_{t}=c_{t}+i_{t}+g+\frac{\kappa_{P}}{2}\left(\pi_{t}-\bar{\pi}\right)^{2} y_{t}+\frac{\kappa_{F G} n_{t-1}}{2}\left(\frac{l_{t-1}^{G}}{l_{t-1}}-b^{*}\right)^{2} .
$$

Total volume of green and brown bonds:

$$
\begin{aligned}
b_{t}^{G} & =q_{t} k_{t}^{G} \\
b_{t}^{B} & =q_{t} k_{t}^{B} .
\end{aligned}
$$

Bonds market clearing:

$$
\begin{aligned}
b_{t}^{G} & =b_{F t}^{G}+b_{P t}^{G} \\
b_{t}^{B} & =b_{F t}^{B}+b_{P t}^{B} \\
b_{t} & =b_{t}^{G}+b_{t}^{B} .
\end{aligned}
$$

Total factor productivity:

$$
A_{t}=\left[1-\left(d_{0}+d_{1} x_{t}+d_{2} x_{t}^{2}\right)\right] a_{t} .
$$


Law of motion of pollution (atmospheric carbon):

$$
x_{t}=\left(1-\delta_{x}\right) x_{t-1}+e_{t}+e^{r o w} .
$$

Emissions function:

$$
e_{t}=\left(y_{t}^{B}\right)^{1-\psi}
$$

Fraction of bonds held by the central bank out of total bonds:

$$
\mu_{t}=\frac{b_{P t}}{b_{t}}
$$

Fraction of green bonds held by the central bank out of total central bank's bonds:

$$
\mu_{t}^{G}=\frac{b_{P t}^{G}}{b_{P t}}
$$

Central bank's total bonds:

$$
b_{P t}=b_{P t}^{G}+b_{P t}^{B} .
$$

Interest rate rule:

$$
\frac{r_{t}}{r}=\left(\frac{r_{t-1}}{r}\right)^{\rho_{r}}\left[\left(\frac{\pi_{t}}{\bar{\pi}}\right)^{\phi_{\pi}}\left(\frac{y_{t}}{y}\right)^{\phi_{y}}\right]^{1-\rho_{r}}
$$

QE Rule

$$
\frac{\mu_{t}}{\bar{\mu}}=\left(\frac{\mu_{t-1}}{\bar{\mu}}\right)^{\rho_{\mu}}\left[\left(\frac{s p_{t}^{G}}{s p}\right)^{\phi_{\mu}}\left(\frac{s p_{t}^{B}}{s p}\right)^{\phi_{\mu}}\right]^{1-\rho_{\mu}} \exp \left(v_{t}^{q e}\right) .
$$

Green QE rule:

$$
\frac{\mu_{t}^{G}}{\bar{\mu}^{G}}=\left(\frac{\mu_{t-1}^{G}}{\bar{\mu}^{G}}\right)^{\rho_{G}}\left[\left(\frac{y_{B t}}{y_{B}}\right)^{\phi_{G}}\right]^{1-\rho_{G}} \exp \left(v_{t}^{g q e}\right) .
$$

Exogenous TFP process:

$$
\log \left(a_{t}\right)=\left(1-\rho_{a}\right) \log (\bar{a})+\rho_{a} \log \left(a_{t-1}\right)+v_{t}^{a} .
$$




\section{B The Steady State}

We compute the steady state using the following procedure. We set the steady-state level of pollution $x$ ex-ante and we compute $\zeta$ ex post. We also set $e^{\text {row }}=3 e$. Using (A.37) we get $e$ :

$$
e=\delta_{x} \frac{x}{4}
$$

Using (A.38) we get $y^{B}$ :

$$
y^{B}=e^{\frac{1}{1-\psi}}
$$

Using (A.46) and $a=1$ we get $A$ :

$$
A=\left[1-\left(d_{0}+d_{1} x+d_{2} x^{2}\right)\right]
$$

In steady state, equations (A.18), (A.21), (A.22) form a system of 3 equations and 3 unknowns $(l, s p, \nu)$, which can be solved with a numerical solver:

$$
\begin{gathered}
l=\frac{\nu}{\theta-\beta(\nu \cdot s p)} \\
1=\chi\left(s p \cdot l+\frac{1}{\beta}\right)+\iota \cdot l . \\
\nu=\chi+(1-\chi) \beta \nu\left[s p \cdot l+\frac{1}{\beta}\right],
\end{gathered}
$$

where:

$$
s p^{G}=s p^{B}=s p
$$

The Taylor rule, the Phillips curve and the Euler equation jointly yield:

$$
\begin{array}{r}
\pi=\bar{\pi} \\
r=\frac{\pi}{\beta} \\
p^{I}=\frac{\varepsilon-1}{\varepsilon} .
\end{array}
$$

The Tobin Q equation yields $q=1$. Use the spread definition to find $r^{G}$ and $r^{B}$ :

$$
r^{G}=r^{B}=s p+\frac{1}{\beta}
$$


Use equations (A.16)-(A.17) to find the rental rate of capital:

$$
r_{k}^{G}=r_{k}^{B}=\left[r^{G}-(1-\delta)\right]
$$

From now on we express all the equations as a function of $y$ and $p_{B}$. Parameter $\zeta$ :

$$
\zeta=\frac{y_{B}}{\left(\frac{p_{B}}{p^{I}}\right)^{-\xi} y} .
$$

If $\xi \neq 1$, we get:

$$
p^{G}=\frac{1}{1-\zeta}\left[\left(p^{I}\right)^{1-\xi}-\zeta\left(p^{B}\right)^{1-\xi}\right]^{\frac{1}{1-\xi}}
$$

If $\xi=1$, we get:

$$
p^{G}=\left[(1-\zeta)^{1-\zeta} \zeta^{\zeta} p^{I}\left(p^{B}\right)^{-\zeta}\right]^{\frac{1}{1-\zeta}} .
$$

Using (A.7) we get green output:

$$
y^{G}=(1-\zeta)\left[\frac{p^{G}}{p^{I}}\right]^{-\zeta} y .
$$

Using (A.15), we get brown capital:

$$
k^{B}=\alpha \frac{p^{B} y^{B}}{r^{B}}
$$

Using (A.15), we get green capital:

$$
k^{G}=\alpha \frac{p^{G} y^{G}}{r^{G}} .
$$

Using the two production functions of basic firms (A.11) and (A.11) we get:

$$
\begin{aligned}
h^{B} & =\left[\frac{y^{B}}{A\left(k^{B}\right)^{\alpha}}\right]^{\frac{1}{1-\alpha}} \\
h^{G} & =\left[\frac{y^{G}}{A\left(k^{G}\right)^{\alpha}}\right]^{\frac{1}{1-\alpha}} .
\end{aligned}
$$

Using capital market clearing (A.29) we get capital:

$$
k=k^{G}+k^{B} .
$$


Using the law of motion of capital (A.4) we get investment:

$$
i=\delta k \text {. }
$$

Using labor demand in the green sector (A.13) we get the wage:

$$
w=(1-\alpha) \frac{p^{G} y^{G}}{h^{G}}
$$

Using labor market clearing (A.29) we get aggregate labor:

$$
h=h^{B}+h^{G} .
$$

Using equation (A.30) we get consumption:

$$
c=y-i-\bar{g} y
$$

where $\bar{g}$ is the public spending ratio over GDP, which is a parameter of the model. Equations (A.50)-(A.62) are functions of $y$ and $p^{B}$ only. This implies that we can find $y$ and $p^{B}$ by solving the following system of two equations (A.13 and A.3), using a numerical solver:

$$
\begin{aligned}
w & =(1-\alpha) p^{B} \frac{y^{B}}{h^{B}} \\
1 & =\frac{w}{c^{\sigma} h^{\varphi}} .
\end{aligned}
$$

Notice that we have derived all the steady-state values of real and environmental variables without using $\mu^{G}$ and $\mu$ : this implies that the steady state is independent from QE and Green QE. This result does not change if we fix $\zeta$ ex ante and compute $x$ ex post.

The remaining steady-state values can be easily found using the remaining equations. 


\section{The Efficient Allocation}

The social planner allocation comprises 17 equations for 17 endogenous variables:

$$
X_{e t} \equiv\left[h_{e t}, h_{e t}^{G}, h_{e t}^{B}, c_{e t}, y_{e t}, k_{e t}, k_{e t}^{B}, k_{e t}^{G}, i_{e t}, q_{e t}, y_{e t}^{G}, y_{e t}^{B}, p_{e t}^{G}, p_{e t}^{B}, p_{e t}^{X}, x_{e t}\right]
$$

The allocation features 1 exogenous shock $v_{t}^{a}$. The 17 equations are the following.

$$
\begin{aligned}
0 & =(1-\alpha) p_{e t}^{B} \frac{y_{e t}^{B}}{h_{e t}^{B}}-h_{e t}^{\varphi} c_{e t}^{\sigma} \\
0 & =(1-\alpha) p_{e t}^{G} \frac{y_{e t}^{G}}{h_{e t}^{G}}-h_{e t}^{\varphi} c_{e t}^{\sigma} \\
1 & =q_{e t}\left\{1-\frac{\kappa_{I}}{2}\left(\frac{i_{e t}}{i_{e t-1}}-1\right)^{2}-\kappa_{I} \frac{i_{e t}}{i_{e t-1}}\left(\frac{i_{e t}}{i_{e t-1}}-1\right)\right\}+ \\
& +\beta \mathbb{E}_{t}\left[\left(\frac{c_{e t}}{c_{e t+1}}\right)^{\sigma} q_{e t+1}\left(\frac{i_{e t+1}}{i_{e t}}\right)^{2} \kappa_{I}\left(\frac{i_{e t+1}}{i_{e t}}-1\right)\right] \\
q_{e t} & =\beta \mathbb{E}_{t}\left[\left(\frac{c_{e t}}{c_{e t+1}}\right)^{\sigma}\left(\frac{\alpha p_{e t+1}^{G} y_{e t+1}^{G}}{k_{e t}^{G}}+(1-\delta) q_{e t+1}\right)\right] \\
q_{e t} & =\beta \mathbb{E}_{t}\left[\left(\frac{c_{e t+1}}{c_{e t}}\right)^{\sigma}\left(\frac{\alpha p_{e t+1}^{B} y_{e t+1}^{B}}{k_{e t}^{B}}+(1-\delta) q_{e t+1}\right)\right] \\
y_{e t}^{G} & =\left[1-\left(D_{0}+D_{1} x_{e t}+D_{2} x_{e t}^{2}\right)\right] a_{t}\left(k_{e t-1}^{G}\right)^{\alpha} h_{e t}^{G(1-\alpha)} \\
y_{e t}^{B} & =\left[1-\left(D_{0}+D_{1} x_{e t}+D_{2} x_{e t}^{2}\right)\right] a_{t}\left(k_{e t-1}^{B}\right)^{\alpha} h_{e t}^{B(1-\alpha)} \\
p_{e t}^{B} & =\zeta^{\frac{1}{\xi}}\left(\frac{y_{e t}^{B}}{y_{e t}}\right)^{-\frac{1}{\xi}}-(1-\psi)\left(y_{e t}^{B}\right)^{-\psi} p_{e t}^{x} \\
y_{e t} & =\left[(1-\zeta)\left(y_{e t}^{G}\right)^{\frac{\xi-1}{\xi}}+\zeta y_{e t}^{B} \frac{\xi-1}{\xi}\right]^{\frac{\xi}{\xi-1}} \\
y_{e t}^{G} & =c_{e t}+i_{e t}+g \\
& =(1-\zeta)^{\frac{1}{\xi}}\left(\frac{y_{e t}^{G}}{\xi}\right.
\end{aligned}
$$




$$
\begin{aligned}
k_{e t} & =(1-\delta) k_{e t-1}+\left[1-\frac{\kappa_{I}}{2}\left(\frac{i_{e t}}{i_{e t-1}}-1\right)^{2}\right] i_{e t} \\
k_{e t} & =k_{e t}^{G}+k_{e t}^{B} \\
h_{e t} & =h_{e t}^{G}+h_{e t}^{B} \\
p_{e t}^{X} & =\frac{\left(D_{1}+2 D_{2} x_{e t}\right)}{\left[1-\left(D_{0}+D_{1} x_{e t}+D_{2} x_{e t}^{2}\right)\right]}\left(p_{x t}^{G} y_{x t}^{G}+p_{x t}^{B} y_{x t}^{B}\right)+\beta\left(1-\delta_{x}\right) \mathbb{E}_{t}\left[\left(\frac{c_{e t}}{c_{e t+1}}\right)^{\sigma} p_{e t+1}^{x}\right] \\
x_{e t} & =\left(1-\delta_{x}\right) x_{e t-1}+\left(y_{e t}^{B}\right)^{1-\psi}+e^{r o w} \\
\log \left(a_{t}\right) & =\left(1-\rho_{a}\right) \log (\bar{a})+\rho_{a} \log \left(a_{t-1}\right)+v_{t}^{a} .
\end{aligned}
$$




\section{RECENTLY PUBLISHED “TEMI” (*)}

N.1294 - Prudential policies, credit supply and house prices: evidence from Italy, by Pierluigi Bologna, Wanda Cornacchia and Maddalena Galardo (September 2020).

N. 1295 - How loose, how tight? A measure of monetary and fiscal stance for the euro area, by Nicoletta Batini, Alessandro Cantelmo, Giovanni Melina and Stefania Villa (September 2020).

N.1296 - Price dividend ratio and long-run stock returns: a score driven state space model, by Davide Delle Monache, Ivan Petrella and Fabrizio Venditti (September 2020).

N.1297 - Workforce aging, pension reforms, and firm outcomes, by Francesca Carta, Francesco D'Amuri and Till von Wachter (September 2020).

N.1298 - Anti-poverty measures in Italy: a microsimulation analysis, by Nicola Curci, Giuseppe Grasso, Pasquale Recchia and Marco Savegnago (September 2020).

N.1299 - Forecasting US recessions: the role of economic uncertainty, by Valerio Ercolani and Filippo Natoli (September 2020).

N. 1300 - Demographics and the natural real interest rate: historical and projected paths for the euro area, by Andrea Papetti (November 2020).

N.1301 - A quantitative analysis of distortions in managerial forecasts, by Yueran Ma, Tiziano Ropele, David Sraer and David Thesmar (November 2020).

N. 1302 - Bargaining power and the Phillips curve: a micro-macro analysis, by Marco J. Lombardi, Marianna Riggi and Eliana Viviano (November 2020).

N.1303 - The effects of structural reforms: Evidence from Italy, by Emanuela Ciapanna, Sauro Mocetti and Alessandro Notarpietro (November 2020).

N.1304 - Consumption and Wealth: New Evidence from Italy, by Riccardo De Bonis, Danilo Liberati, John Muellbauer and Concetta Rondinelli (November 2020).

N.1305 - Do details matter? An analysis of the Italian personal income tax, by Martino Tasso (November 2020).

N. 1306 - Effects of eligibility for central bank purchases on corporate bond spreads, by Taneli Mäkinen, Fan Li, Andrea Mercatanti and Andrea Silvestrini (November 2020).

N. 1307 - On the design of grant assignment rules, by Francesca Modena, Santiago Pereda Fernandez and Giulia Martina Tanzi (December 2020).

N. 1308 - Monetary policy strategies in the New Normal: a model-based analysis for the euro area, by Fabio Busetti, Stefano Neri, Alessandro Notarpietro and Massimiliano Pisani (December 2020).

N.1309 - Rare disasters, the natural interest rate and monetary policy, by Alessandro Cantelmo (December 2020).

N.1310 - The market stabilization role of central bank asset purchases: high-frequency evidence from the COVID-19 crisis, by Marco Bernardini and Annalisa De Nicola (December 2020).

N.1311 - Equity tail risk in the treasury bond market, by Dario Ruzzi and Mirco Rubin (December 2020).

N. 1312 - Scars of youth non-employment and labour market conditions, by Giulia Martina Tanzi (December 2020).

N. 1313 - The COVID-19 shock and a fiscal-monetary policy mix in a monetary union, by Anna Bartocci, Alessandro Notarpietro and Massimiliano Pisani (December 2020).

(*) Requests for copies should be sent to:

Banca d'Italia - Servizio Studi di struttura economica e finanziaria - Divisione Biblioteca e Archivio storico - Via Nazionale, 91 - 00184 Rome - (fax 003906 47922059). They are available on the Internet www.bancaditalia.it. 
ALBANESE G., M. CIOFFI and P. TOMMASINO, Legislators' behaviour and electoral rules: evidence from an Italian reform, European Journal of Political Economy, v. 59, pp. 423-444, WP 1135 (September 2017).

Aprigliano V., G. ARDizzI and L. MONTEFORTE, Using the payment system data to forecast the economic activity, International Journal of Central Banking, v. 15, 4, pp. 55-80, WP 1098 (February 2017).

ARnAudo D., G. MiCUCCI, M. RIGON and P. Rossi, Should I stay or should I go? Firms' mobility across banks in the aftermath of the financial crisis, Italian Economic Journal / Rivista italiana degli economisti, v. 5, 1, pp. 17-37, WP 1086 (October 2016).

BASSO G., F. D'AMURI and G. PERI, Immigrants, labor market dynamics and adjustment to shocks in the euro area, IMF Economic Review, v. 67, 3, pp. 528-572, WP 1195 (November 2018).

BAtini N., G. MELINA and S. VILla, Fiscal buffers, private debt, and recession: the good, the bad and the ugly, Journal of Macroeconomics, v. 62, WP 1186 (July 2018).

Burlon L., A. NotARPIETRO and M. PISANI, Macroeconomic effects of an open-ended asset purchase programme, Journal of Policy Modeling, v. 41, 6, pp. 1144-1159, WP 1185 (July 2018).

BUSETTI F. and M. CAIVANO, Low frequency drivers of the real interest rate: empirical evidence for advanced economies, International Finance, v. 22, 2, pp. 171-185, WP 1132 (September 2017).

CAPpelletti G., G. GuAZZAROtTI and P. TOMmasino, Tax deferral and mutual fund inflows: evidence from a quasi-natural experiment, Fiscal Studies, v. 40, 2, pp. 211-237, WP 938 (November 2013).

CARDANi R., A. PACCAGNINI and S. VILLA, Forecasting with instabilities: an application to DSGE models with financial frictions, Journal of Macroeconomics, v. 61, WP 1234 (September 2019).

Chiades P., L. Greco, V. Mengotto, L. Moretti and P. VAlbonesi, Fiscal consolidation by intergovernmental transfers cuts? The unpleasant effect on expenditure arrears, Economic Modelling, v. 77, pp. 266-275, WP 1076 (July 2016).

CIANI E., F. DAVID and G. DE BLASIO, Local responses to labor demand shocks: a re-assessment of the case of Italy, Regional Science and Urban Economics, v. 75, pp. 1-21, WP 1112 (April 2017).

CIANI E. and P. FISHER, Dif-in-dif estimators of multiplicative treatment effects, Journal of Econometric Methods, v. 8. 1, pp. 1-10, WP 985 (November 2014).

CIAPANNA E. and M. TABOGA, Bayesian analysis of coefficient instability in dynamic regressions, Econometrics, MDPI, Open Access Journal, v. 7, 3, pp.1-32, WP 836 (November 2011).

Coletta M., R. De Bonis and S. Piermattei, Household debt in OECD countries: the role of supply-side and demand-side factors, Social Indicators Research, v. 143, 3, pp. 1185-1217, WP 989 (November 2014).

Cova P., P. PAgAno and M. PISANI, Domestic and international effects of the Eurosystem Expanded Asset Purchase Programme, IMF Economic Review, v. 67, 2, pp. 315-348, WP 1036 (October 2015).

ERCOLANI V. and J. VALLE E AZEVEDO, How can the government spending multiplier be small at the zero lower bound?, Macroeconomic Dynamics, v. 23, 8. pp. 3457-2482, WP 1174 (April 2018).

FERrERo G., M. GROSS and S. NERI, On secular stagnation and low interest rates: demography matters, International Finance, v. 22, 3, pp. 262-278, WP 1137 (September 2017).

FoA G., L. GAmBACORTA, L. Guiso and P. E. Mistrulli, The supply side of household finance, Review of Financial Studies, v.32, 10, pp. 3762-3798, WP 1044 (November 2015).

GerAli A. and S. NERI, Natural rates across the Atlantic, Journal of Macroeconomics, v. 62, article 103019, WP 1140 (September 2017).

GIORDANO C., M. MARINUCCI and A. SILVESTRINI, The macro determinants of firms' and households' investment: evidence from Italy, Economic Modelling, v. 78, pp. 118-133, WP 1167 (March 2018).

GOMEllini M., D. PELlEGRINO and F. GIFFONI, Human capital and urban growth in Italy, 1981-2001, Review of Urban \& Regional Development Studies, v. 31, 2, pp. 77-101, WP 1127 (July 2017).

LiBERATI D. and M. LOBERTO, Taxation and housing markets with search frictions, Journal of Housing Economics, v. 46, article 101632, WP 1105 (March 2017).

MAGRI S., Are lenders using risk-based pricing in the Italian consumer loan market? The effect of the 2008 crisis, Journal of Credit Risk, v. 15, 1, pp. 27-65, WP 1164 (January 2018).

Mercatanti A., T. MAKINEN and A. SiLVESTRINI, The role of financial factors for european corporate investment, Journal of International Money and Finance, v. 96, pp. 246-258, WP 1148 (October 2017). 
Miglietta A., C. Picillo and M. PIETRUnTI, The impact of margin policies on the Italian repo market, The North American Journal of Economics and Finance, v. 50, WP 1028 (October 2015).

MONTEFORTE L. and V. RAPONI, Short-term forecasts of economic activity: are fortnightly factors useful?, Journal of Forecasting, v. 38, 3, pp. 207-221, WP 1177 (June 2018).

Neri S. and A. NotArpietro, Collateral constraints, the zero lower bound, and the debt-deflation mechanism, Economics Letters, v. 174, pp. 144-148, WP 1040 (November 2015).

PANCRAZI R. and M. PIETRUNTI, Natural expectations and home equity extraction, Journal of Housing Economics, v. 46, 4, WP 984 (November 2014).

Pereda FERnANDEZ S., Teachers and cheaters. Just an anagram?, Journal of Human Capital, v. 13, 4, pp. 635-669, WP 1047 (January 2016).

RigGi M., Capital destruction, jobless recoveries, and the discipline device role of unemployment, Macroeconomic Dynamics, v. 23, 2, pp. 590-624, WP 871 (July 2012).

AlessANDRi P. and M. BOTTERO, Bank lending in uncertain times, R European Economic Review, V. 128, WP 1109 (April 2017).

Antunes A. and V. ERCOlAnI, Public debt expansions and the dynamics of the household borrowing constraint, Review of Economic Dynamics, v. 37, pp. 1-32, WP 1268 (March 2020).

ARDUINI T., E. PATACCHINI and E. RAINONE, Treatment effects with heterogeneous externalities, Journal of Business \& Economic Statistics, , v. 38, 4, pp. 826-838, WP 974 (October 2014).

Bottero M., F. MeZZANOTTI and S. LENZU, Sovereign debt exposure and the Bank Lending Channel: impact on credit supply and the real economy, Journal of International Economics, v. 126, article 103328, WP 1032 (October 2015).

BRIPI F., D. LOSCHIAVO and D. REVELLI, Services trade and credit frictions: evidence with matched bankfirm data, The World Economy, v. 43, 5, pp. 1216-1252, WP 1110 (April 2017).

BRONZINI R., G. CARAMELLINO and S. MAGRI, Venture capitalists at work: a Diff-in-Diff approach at latestages of the screening process, Journal of Business Venturing, v. 35, 3, WP 1131 (September 2017).

BronzINI R., S. MocetTI and M. MONGARDINI, The economic effects of big events: evidence from the Great Jubilee 2000 in Rome, Journal of Regional Science, v. 60, 4, pp. 801-822, WP 1208 (February 2019).

COIBION O., Y. GORODNICHENKO and T. ROPELE, Inflation expectations and firms' decisions: new causal evidence, Quarterly Journal of Economics, v. 135, 1, pp. 165-219, WP 1219 (April 2019).

CORSELlO F. and V. NiSPI LANDI, Labor market and financial shocks: a time-varying analysis, Journal of Money, Credit and Banking, v. 52, 4, pp. 777-801, WP 1179 (June 2018).

COVA P. and F. NATOLI, The risk-taking channel of international financial flows, Journal of International Money and Finance, v. 102, WP 1152 (December 2017).

D'Alessio G., Measurement errors in survey data and the estimation of poverty and inequality indices, Statistica Applicata - Italian Journal of Applied Statistics, v. 32, 3, WP 1116 (June 2017).

Del Prete S. and S. FEDERICO, Do links between banks matter for bilateral trade? Evidence from financial crises, Review of World Economic, v. 156, 4, pp. 859 - 885, WP 1217 (April 2019).

D'IGNAZIO A. and C. MENON, The causal effect of credit Guarantees for SMEs: evidence from Italy, The Scandinavian Journal of Economics, v. 122, 1, pp. 191-218, WP 900 (February 2013).

ERCOLANI V. and F. NATOLI, Forecasting US recessions: the role of economic uncertainty, Economics Letters, v. 193, WP 1299 (October 2020).

MAKINEN T., L. SARNO and G. ZINNA, Risky bank guarantees, Journal of Financial Economics, v. 136, 2, pp. 490522, WP 1232 (July 2019).

MOdEnA F., E. RETTORE and G. M. TANZI, The effect of grants on university dropout rates: evidence from the Italian case, Journal of Human Capital, v. 14, 3, pp. 343-370, WP 1193 (September 2018).

NiSPI LANDI V., Capital controls spillovers, Journal of International Money and Finance, v. 109, WP 1184 (July 2018).

PERICOLI M., On risk factors of the stock-bond correlation, International Finance, v. 23, 3, pp. 392-416, WP 1198 (November 2018). 
RAINONE E., The network nature of OTC interest rates, Journal of Financial Markets, v.47, article 100525, WP 1022 (July 2015).

RAINONE E. and F. VACIRCA, Estimating the money market microstructure with negative and zero interest rates, Quantitative Finance, v. 20, 2, pp. 207-234, WP 1059 (March 2016).

RIZZICA L., Raising aspirations and higher education. Evidence from the UK's widening participation policy, Journal of Labor Economics, v. 38, 1, pp. 183-214, WP 1188 (September 2018).

SANTIONI, R., F. SCHIANTARELLI and P. STRAHAN, Internal capital markets in times of crisis: the benefit of group affiliation, Review of Finance, v. 24, 4, pp. 773-811, WP 1146 (October 2017).

SChiantarelli F., M. Stacchini and P. Strahan, Bank Quality, judicial efficiency and loan repayment delays in Italy, Journal of Finance, v. 75, 4, pp. 2139-2178, WP 1072 (July 2016).

\section{FORTHCOMING}

Accetturo A., A. LAmorgese, S. Mocetti and D. Pellegrino, Housing Price elasticity and growth: evidence from Italian cities, Journal of Economic Geography, WP 1267 (March 2020).

AlBAnese G., E. CIANI and G. DE BLASIO, Anything new in town? The local effects of urban regeneration policies in Italy, Regional Science and Urban Economics, WP 1214 (April 2019).

Albanese G., G. DE BlAsio and A. LOCATELLI, Does EU regional policy promote local TFP growth? Evidence from the Italian Mezzogiorno, Papers in Regional Science, WP 1253 (December 2019).

ANZUINI A. and L. Rossi, Fiscal policy in the US: a new measure of uncertainty and its effects on the American economy, Empirical Economics, WP 1197 (November 2018).

Bologna P., A. Miglietta and A. Segura, Contagion in the CoCos market? A case study of two stress events, International Journal of Central Banking, WP 1201 (November 2018).

Cova P., P. PAgAnO, A. NotARPIETRO and M. PisAni, Secular stagnation, R\&D, public investment and monetary policy: a global-model perspective, Macroeconomic Dynamics, WP 1156 (December 2017).

DE PHILIPPIS M., Multitask agents and incentives: the case of teaching and research for university professors, Economic Journal, WP 1156 (December 2015).

Del Prete S. and M. L. SteFAni, Women as "Gold Dust": gender diversity in top boards and the performance of Italian banks, Economic Notes, Monte dei Paschi di Siena, WP 1014 (June 2015).

Fidora M., C. GIORDANO and M. SchMitz, Real exchange rate misalignments in the Euro Area, Open Economies Review, WP 1042 (January 2018).

HERTWECK M., V. LEWIS and S. VILLA, Going the extra mile: effort by workers and job-seekers, Journal of Money, Credit and Banking, WP 1277 (June 2020).

Li F., A. MercatAnti, T. MAKINEN and A. SilveSTRINI, A regression discontinuity design for ordinal running variables: evaluating central bank purchases of corporate bonds, Annals of Applied Statistics, WP 1213 (March 2019).

LOSCHIAVO D., Household debt and income inequality: evidence from Italian survey data, Review of Income and Wealth, WP 1095 (January 2017).

METELli L. and F. NATOLI, The international transmission of US tax shocks: a proxy-SVAR approach, IMF Economic Review, WP 1223 (June 2019).

Mocetti S., G. RomA and E. RuBOLINO, Knocking on parents' doors: regulation and intergenerational mobility, Journal of Human Resources, WP 1182 (July 2018).

NisPi LANDI V. and A. SCHIAVONE, The effectiveness of capital controls, Open Economies Review, WP 1200 (November 2018).

PeReda Fernandez S., Copula-based random effects models for clustered data, Journal of Business \& Economic Statistics, WP 1092 (January 2017).

PERICOLI M. and M. TABOGA, Nearly exact Bayesian estimation of non-linear no-arbitrage term-structure models, Journal of Financial Econometrics, WP 1189 (September 2018). 